\title{
External Constraints and Endogenous Growth: Why Didn't Some Countries Benefit From Capital Flows?*
}

\author{
Karine GENTE \\ Aix-Marseille University (Aix-Marseille School of Economics), CNRS 83 EHESS \\ Miguel A. LEÓN-LEDESMA \\ University of Kent \\ Carine NOURRY \\ Aix-Marseille University (Aix-Marseille School of Economics), CNRS \& EHESS and IUF
}

\begin{abstract}
Empirical evidence on the growth benefits of capital inflows is mixed. The growth benefits accruing from capital inflows also appear to be larger for high savings countries. We explain this phenomenon using an OLG model of endogenous growth in open economies with borrowing constraints that can generate both positive and negative growth effects of capital inflows. The amount an economy can borrow is restricted by an endogenous enforcement constraint. In our setting, with physical capital and a pay-as-you-go pensions system, the steady state is unique. However, it can either be constrained or unconstrained. In a constrained economy, opening up to equity and FDI inflows can be bad for growth because it makes the domestic interest rate too low, which endogenously tightens borrowing constraints. Agents decrease savings and investment in productivity-enhancing activities resulting in lower growth. Results are reversed in an unconstrained economy. We also provide a quantitative analysis of these constraints and some policy implications.
\end{abstract}

Keywords: Overlapping generations, endogenous credit constraint, capital flows, endogenous growth.

JEL Classification Numbers: F43, F34.

*Gente: DEFI, Aix-Marseilles Univ, Chateau Lafarge, Route des Milles, 13290 Aix-en-Provence, FRANCE, e-mail: karine.gente@univmed.fr. León-Ledesma: School of Economics, Keynes College, University of Kent, Canterbury, CT27NP, UK, email: m.a.leon-ledesma@kent.ac.uk. Nourry: GREQAM, Centre de la Vieille Charité 2 Rue de la Charité 13236 Marseille Cedex 02, email: carine.nourry@univ-amu.fr. This study is supported in part by NSF grant \#0720839 and by the French National Research Agency grant (ANR-12-GLOB-0005-01). We thank Joshua Aizenman, Gianluca Benigno, Matthieu Bussiere, Menzie Chinn, Mick Devereux, Michel Normandin, Thomas Seegmuller and seminar participants at various workshops and seminars for useful comments and suggestions. 


\section{Introduction}

The effect of capital inflows on growth during the period of financial globalization in the world economy has attracted a lot of interest in recent years. This interest has been reinforced by the decline and lack of recovery in cross-border capital flows for rich and middle income countries after the Global Financial Crisis. ${ }^{1}$ Whether these trends will have long-run consequences for growth is an open question. Textbook economic theory would predict that capital inflows should be conducive to growth as capital moves towards economies with better investment opportunities and is a source of technological spillovers. However, empirical evidence has failed to find a robust association between these variables. A substantial body of empirical evidence has emerged in recent years ${ }^{2}$ showing that the growth impact of capital flows appears elusive. The impact depends on variables such as the level of economic development, financial depth, institutional quality, and the nature of capital flows. Also, most gains are associated to TFP growth rather than capital accumulation. The external asset position of countries also appears to matter. A puzzling observation commonly found in the literature is that there is a positive correlation between net capital outflows and growth (see Prasad et al, 2007). Countries running current account surpluses and with higher savings rates grew faster than capital importing countries, leading to the so-called "capital allocation puzzle". 3

We present a model that attempts to explain this evidence by focusing on the role played by international credit constraints within an overlapping generations (OLG) endogenous growth setting. The model is able to generate either positive or negative growth effects of capital inflows as well as a role for domestic savings for the success of liberalization policies. Contrary to the emphasis in much of the previous literature, our focus here is on countries whose autarky interest rate is above the world interest rate such that, when opening up, they would run current account deficits. In this sense, our approach departs from the literature on the Lucas paradox, but complements it by analyzing the growth effects of capital inflows in deficit economies. The endogenous growth setting also allows us to discuss long-run growth rather than simply transitional dynamics. The model departs from the small open economy (SOE) setting assuming that foreign investment is restricted to be a percentage of the capital stock of the economy. ${ }^{4}$ This restriction is exogenous, and we use changes in it to model capital account liberalizations. However, the amount agents can borrow in

\footnotetext{
${ }^{1}$ See McKinsey Global Institute (2013).

${ }^{2}$ See, among others, Aizenman and Sushko (2011), Beckaert et al (2005, 2011), Kose et al (2011), Kose et al (2009), Obstfeld (2009), and Prasad et al (2007).

${ }^{3}$ See Gourinchas and Jeanne (2013).

${ }^{4}$ Foreign investment in our model is a claim on the physical capital stock of the country, which includes FDI and equity inflows.
} 
international credit markets is endogenously determined. ${ }^{5}$ In this framework, agents cannot commit with collateral and there are enforcement constraints that determine how much agents can borrow on credit markets. Our endogenous growth setting has a reproducible factor that generates externalities and leads to permanent growth in steady state. ${ }^{6}$ For simplicity, we will call this factor "human-capital". We also introduce physical capital accumulation and a pay-as-you-go pension system. This allows us to have determinacy and a unique steady state which can either be constrained or unconstrained and the impact of capital flows on growth depends on the nature of the steady state.

Our model is better thought of as representing the case of an emerging market with high domestic marginal product of capital and with a history of past debt commitment problems potentially preventing it from borrowing optimally. The effect of opening up to capital inflows will depend on the steady state, which is a function of the savings rate, human capital externalities, and the pensions system among other variables. The intuition behind this result is that a rise in foreign investment inflows tends to increase physical capital and thus lower its marginal product. Since we focus on the case where the domestic interest rate exceeds the world interest rate, agents borrow in international credit markets to finance investment in human capital. When they enter the economy, agents choose their level of education financed by a credit. Since they cannot commit, they can choose to either reimburse or not this loan when they are middle-aged. If they reimburse, they can benefit from access to asset markets and save between their middle-age and old-age. If they default, they cannot participate in asset markets, and only consume the pension when they are old. This is because, otherwise, their assets would be seized by international financial markets. The higher the domestic interest rate, the more incentive agents have to refund their loan since the return on savings is higher. We thus obtain that the impact of capital inflows on growth depends on the nature of the steady state. In both steady states it leads to a rise in physical capital, a decrease in the domestic interest rate and a rise in domestic wages. In a constrained economy, however, domestic interest rates are too low and agents have no incentives to refund their loans. As a result, the amount they can borrow will be endogenously constrained and they under-invest in education. As a consequence, growth falls. In an unconstrained economy, on the other hand, domestic interest rates are high enough to encourage agents to refund their loans and they can reach the optimal level of education. Capital inflows then increase growth because they lead to a reduction of domestic interest rates - which still remain high enough - and an increase in wages. The return on human capital is higher and so is the optimal level of education and economic growth. Any factor whose increase is able

\footnotetext{
${ }^{5}$ See Azariadis and Lambertini (2003) and Kehoe and Levine (1993).

${ }^{6}$ See De La Croix and Michel (2007).
} 
to generate a rise in domestic interest rates, such as the rate of time preference, is likely to drive the economy from the constrained to the unconstrained steady state. We thus find that, as in Aghion et al (2009), domestic savings matter for growth.

This setting also allows us to present a quantitative exercise. We first assess the likelihood of economies converging to the constrained steady state given a set of calibrated parameters obtained from data. We then look at what would the required savings rate or public pension outlays be for these economies to converge to the unconstrained steady state. We finally assess the growth effects of increased capital inflows in the model. We carry out this exercise using parameter calibration values for Brazil, Colombia, Chile, Mexico, Greece, Italy and Spain. We find that, for the majority of these economies, there is a high likelihood of converging to the constrained steady state, especially if human capital externalities are high. For a large number of countries, we also find that the savings rate and the public pension outlays required to converge to the unconstrained steady state is much larger (much lower in the case of pension contributions) than the one observed in data. We also find that the growth effects of capital flows are quantitatively very small.

The rest of the paper is organized as follows. Section 2 presents a brief discussion of evidence and the literature. Section 3 presents the model. Section 4 analyzes the equilibrium in a no-commitment setting. Section 5 discusses equilibrium dynamics. Section 6 focuses on the relationship between capital flows and economic growth. Section 7 presents a quantitative exercise, and section 8 concludes.

\section{Literature and evidence: discussion}

Much of the related theoretical literature has focused on the effect of growth on capital flows in a context where liberalizing countries display low autarky interest rates and, as a consequence, export capital as they grow. Prasad et al (2007) and Gourinchas and Jeanne (2013) show that the correlation between per capita GDP growth and the average current account (CA) to GDP ratio is positive and significant. The "capital allocation puzzle" is then that countries that grow fast and invest more tend to be net exporters of capital. Related to this paradox is the phenomenon of Global Imbalances (GIs) and the shift in the sources of world savings from developed to emerging countries since the late 1990s. Special focus has been placed on the role played by China and differential levels of financial sector development to explain these phenomena. Although our paper deals with the opposite situation where countries' autarky interest rate exceeds the world interest rate, it is worth understanding some of the mechanisms relating growth and capital flows in this literature to contextualize our analysis.

The literature on GIs has studied the phenomenon as a consequence of equilibrium 
capital flows placing emphasis on either the supply or demand of assets that allow for risk diversification. Caballero et al (2008), for instance, identify the differential supply of safe assets as the main driving force behind capital flowing from emerging to developed countries. As developed countries offer less volatile and safer returns, savers tilt their portfolios towards countries with deeper financial sectors. An analogous argument is used in Mendoza et al (2009), who focus on the role of limited contract enforcement in emerging countries' financial markets. A large body of literature has since developed to explain the coincidence between the Chinese growth acceleration and GIs. ${ }^{7}$ Several of these papers share in common the existence of a precautionary savings motive and incomplete markets. Because of the impossibility of insuring against idiosyncratic income risk with incomplete markets, a precautionary savings motive arises. This increases the supply of savings and drives a wedge between the marginal product of capital and the interest rate. When these countries liberalize their capital accounts to countries with more risk diversification opportunities and TFP increases, they become net exporters of capital. The focus is mostly on the relationship running from TFP growth to the generation of excess savings and hence CA surpluses. These models are adequate to explain GIs and the experience of countries such as China. However, as Henry (2007) shows, in most cases, capital account liberalizations entail a decrease in the cost of capital implying that they would lead to net capital inflows.

As in our model, Aoki et al (2010) introduce credit constraints using a KiyotakiMoore type ${ }^{8}$ setting with domestic and international borrowing constraints. They show that, when the domestic financial system is underdeveloped, capital account liberalization is not necessarily beneficial for growth because it can lead to TFP stagnation in the long-run or short-run employment losses. Their setting, however, does not consider endogenous growth. The models presented in Aghion et al (2009) and Song et al (2011) also share common features with ours in that domestic savings matter for growth. In Aghion et al (2009) growth is driven by countries acquiring best practice technologies from abroad by attracting FDI. Savings matter because foreign investors require knowledge from local entrepreneurs. Local entrepreneurs, in turn, require savings to put equity in the partnership with foreign investors. In this model, as emphasized by Gourinchas and Jeanne (2013), the causality runs from savings to growth. In Song et al (2011) they explain Chinese growth and high savings rates in terms of the dual structure of Chinese firms with state owned and private firms. Private firms are the source of growth but are credit constrained and hence require savings to expand. These savings arise from the inequality that develops

\footnotetext{
${ }^{7}$ See, for instance, Angeletos and Panousi (2011), Broner and Ventura (2010), Buera and Shin (2009), Carroll and Jeanne (2009), Coeurdacier et al (2013), Sandri (2010) and Song et al (2011) amongst many others.

${ }^{8}$ See Kiyotaki and Moore (1997).
} 
between managers and workers as only managers benefit from growth. This explains the positive correlation between growth and savings and, by implication, the CA.

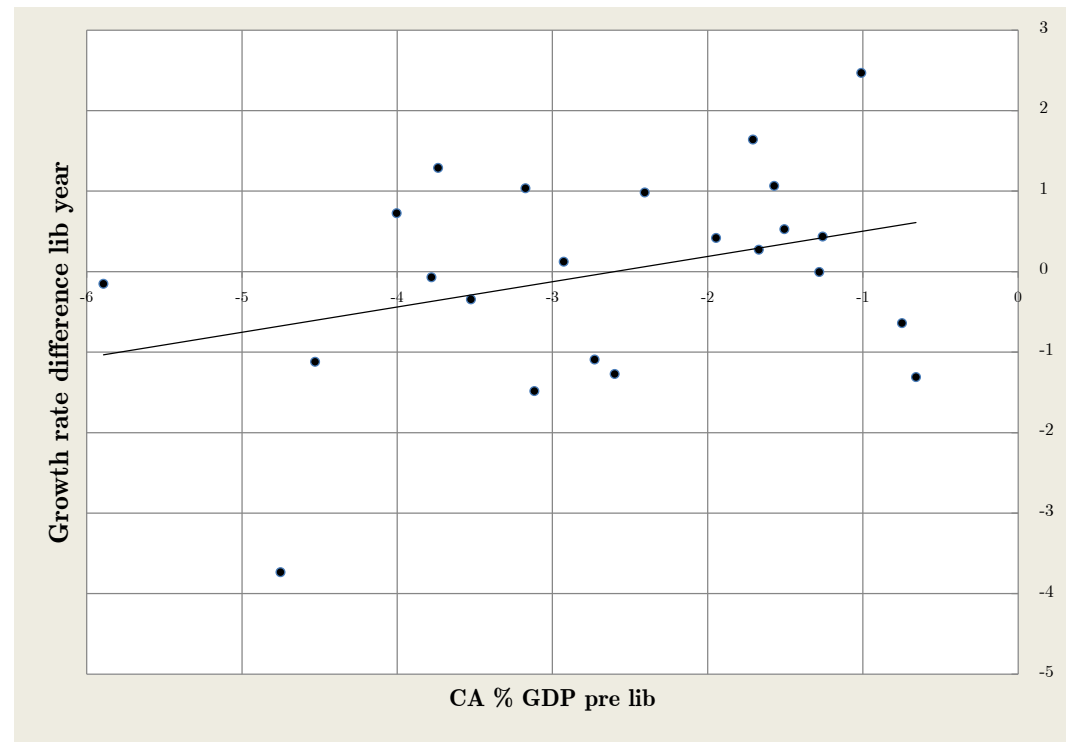

Figure 1: Current account and growth rate difference between post- and pre-liberalization. Deficit countries.

As already noted, most of the literature focuses on savings surplus countries. However, the positive association between the CA and growth also happens for deficit countries. Figure 1 plots the difference between pre- and post-liberalization growth performance against initial CA to GDP ratio for 24 deficit countries between 1975 and $2010 .^{9}$ It shows that the growth success of capital account liberalization policies is positively correlated with the CA. Thus, even for countries that are net foreign borrowers, savings seem to matter for growth after opening up the capital account to capital inflows. Table 1 also shows the growth difference from pre- to post-liberalization periods for three groups of CA deficit countries. ${ }^{10}$ The countries are grouped as high or low savings according to whether domestic savings are above or below the average

\footnotetext{
${ }^{9}$ Countries are classified as deficit countries if the average CA position before the liberalization episode is negative. Periods of capital account liberalization are identified using the Chinn and Ito (2007) index combined with the Lane and Milesi-Ferretti (2007) dataset and a detailed analysis of country policies. We define capital account liberalization as a change of the Chinn-Ito index from negative to positive when this change is substantial (i.e. higher than the average change for the country). We also check whether this is accompanied by a substantial (ex-post) increase in the ratio of foreign assets plus liabilities as a percentage of GDP. Finally, we compared our periods with other available sources about liberalization programmes.

${ }^{10}$ The groups of countries considered are as follows. OECD: Australia, Austria, Canada, Denmark,
} 
of their group. The growth difference in differences between high and low saving countries is always positive.

Table 1: Change in GDP growth before and after capital account liberalization (CA deficit countries)

\begin{tabular}{rrr}
\hline \multirow{2}{*}{ OECD } & Savings rate group Change in growth rate \\
& High & 0.197 \\
& Low & -0.199 \\
\multirow{2}{*}{ Latin America } & Difference High-Low & $\mathbf{0 . 3 9 6}$ \\
& & \\
& High & 0.821 \\
& Low & 0.602 \\
South East Asia & High & -0.143 \\
& Low & -1.309 \\
& Difference High-Low & $\mathbf{1 . 1 6 6}$ \\
\hline
\end{tabular}

Our model thus focuses on deficit countries for which capital inflows may change the incentives to repay back international private loans. This generates an endogenous credit constraint that is determined by a "willingness to pay" motive rather than a "capacity to borrow" motive as in models with exogenous collateral constraints (see Arellano and Mendoza, 2002). The model features endogenous growth and achieves determinacy by introducing capital and a pay-as-you-go pensions system. This allows us to focus on the role of savings and public pension outlays as key determinants of the steady state towards which the economy converges. The return on savings and the pensions system determine income after working age and hence the incentive to repay the credit acquired to build human capital. This, in turn, determines whether opening up to foreign capital inflows will have beneficial or detrimental effects on growth. Given these characteristics, our model is better suited to analyze the experience of Latin American countries and several Southern European countries especially after the sovereign debt turmoil since 2010.

Finland, France, Greece, Italy, Portugal, Spain, Sweden and UK. Latin America: Argentina, Bolivia, Brazil, Chile, Colombia, Costa Rica, Ecuador, Mexico, Paraguay, Peru and Uruguay. South East Asia: Indonesia, Malaysia, Philippines, Singapore, South Korea and Thailand. 


\section{Model}

We consider an overlapping generations model with accumulation of productivity enhancing activities (human capital in a loose sense) and an endogenous credit constraint as in De La Croix and Michel (2007). In this framework, we introduce physical capital accumulation and a pay-as-you-go pension system and assume that the economy has access to international credit markets at the exogenous world interest rate factor $R^{W}$.

\subsection{Production}

Consider a perfectly competitive economy in which final output is produced using physical capital $K$ and human capital $H$, and $t$ denotes the time period. The production function of a representative firm is $F\left(K_{t}, H_{t}\right) \equiv H_{t} f\left(k_{t}\right)$ with $k \equiv K / H$. Capital fully depreciates each period.

Assumption 1. $f(k)$ is $C^{r}$ over $\mathbb{R}_{+}$for $r$ large enough, increasing $\left(f^{\prime}(k)>0\right)$ and concave $\left(f^{\prime \prime}(k)<0\right)$ over $\mathbb{R}_{++}$.

The domestic interest factor $R_{t}$ and the wage rate $w_{t}$ then satisfy:

$$
w_{t}=f\left(k_{t}\right)-k_{t} f^{\prime}\left(k_{t}\right), R_{t}=f^{\prime}\left(k_{t}\right) .
$$

\subsection{Households}

Population growth rate is $n$. The typical household lives for 3 periods. An agent born in $t-1$ draws utility from consumption when middle-aged $c_{t}$ and old $d_{t+1}$

$$
V=u\left(c_{t}, d_{t+1}\right)
$$

Assumption 2. The utility function $u(.,$.$) is increasing in its arguments and con-$ cave; it is homogeneous of degree one (homothetic preferences) and satisfies the Inada conditions.

Individuals born in period $t-1$ borrow an amount $b_{t-1}$ of goods when young to build up their human capital $h_{t}$ for the middle-aged period. When middle-aged, they receive a wage $w_{t} h_{t}$, with $w_{t}$ the wage per unit of efficient labor, and pay a proportional $\operatorname{tax} \tau \in(0,1)$ to finance a balanced pension system. When old, they retire and receive $p_{t+1}=(1+n) \tau w_{t+1} h_{t+1}$ issued from a pay-as-you-go system. Following De La Croix and Michel (2007), we assume that human capital accumulation is given by

$$
h_{t}=A b_{t-1}^{\lambda} h_{t-1}^{1-\lambda}
$$


with education productivity denoted by $A>0$, and $0<\lambda<1$ being the education externality. Human capital depends on individual investment $b_{t-1}$ and on the inherited human capital of the previous generation $h_{t-1}$. This latter effect may be viewed as inter-generational transmission of human capital or as the externality effect of society's education level. In our preferred wider sense, $1-\lambda$ would reflect productivity or knowledge spillovers from the previous generation's stock of technological knowhow on the current generation's stock. $b_{t-1}$ is the investment effort of the current generation on productivity enhancing activities.

Assumption 3. The domestic interest factor $R_{t}$ is greater than the constant world interest factor $R_{W} \forall t .^{11}$

Under this assumption, as interest rates are lower in the international credit market than in the domestic market, households will always prefer to save in the domestic market and borrow in the international market. For simplicity, we assume that agents cannot arbitrage by borrowing internationally and lending at home. This assumption allows us to obtain simpler analytical solutions by ignoring arbitrage profits, but it does not change the uniqueness properties of the steady state. ${ }^{12}$ This can be conceptualized as representing a situation where a national investment bank borrows in international markets on behalf of households for their human capital investment, but households can only save at home and borrow from the national bank. This national bank, in turn, has the ability to seize household savings in case of default as we will see below. We further assume that there is no possibility of collateralizing human capital.

Let us consider successively the agents' choices under a commitment and a nocommitment setting.

\subsection{Optimal decisions in a commitment setting}

In a commitment setting, agents born in $t-1$ refund their loan $b_{t-1}$ at time $t$ and their potential middle-age loan $s_{t}$ at time $t+1$. The variable $s_{t}$ denotes either borrowing or saving. When $s_{t}>0$, agents save at time $t$ on the domestic market and get the domestic return $R_{t+1}$. Thus, the period budget constraints are

$$
\begin{aligned}
c_{t} & =w_{t} h_{t}(1-\tau)-s_{t}-R_{W} b_{t-1}, \\
d_{t+1} & =p_{t+1}+R_{t+1} s_{t},
\end{aligned}
$$

where $R_{W}$ is the interest factor paid on international loans. Under Assumption 3, the debt each young agent contracts to finance her education is a loan from foreigners.

\footnotetext{
${ }^{11}$ This assumption will be satisfied as long as domestic capital intensity in steady state is low enough relative to world capital intensity and initially the domestic capital intensity is not too high.

${ }^{12}$ See Christopoulos et al (2013).
} 
We denote $\omega_{1}$ first period income and $\omega_{2}$ second period income:

$$
\begin{aligned}
\omega_{1 t} & =w_{t} h_{t}(1-\tau)-R_{W} b_{t-1} \\
\omega_{2 t+1} & =p_{t+1}
\end{aligned}
$$

As the level of education determines the life cycle income, and the amount of saving determines the allocation of the consumption between middle age and retirement in order to maximize welfare, the two optimal decisions can be computed independently. We proceed into two steps. First, we determine optimal savings and, second, considering the education level as given, we then compute the optimal education level.

$$
\max _{s_{t}} u\left(\omega_{1 t}-s_{t}, \omega_{2 t+1}+R_{t+1} s_{t}\right) .
$$

The FOC is

$$
-u_{1}^{\prime}\left(c_{t}, d_{t+1}\right)+R_{t+1} u_{2}^{\prime}\left(c_{t}, d_{t+1}\right)=0,
$$

which can be written in implicit form as:

$$
\frac{d_{t+1}}{c_{t}}=\mu\left(R_{t+1}\right)
$$

Then, optimal savings are given by

$$
s_{t}^{*}=\frac{\mu\left(R_{t+1}\right) \omega_{1 t}-\omega_{2 t+1}}{R_{t+1}+\mu\left(R_{t+1}\right)} .
$$

To facilitate the algebra, we define $x_{t}$, the debt repayment as a percentage of income. Using $h_{t}=A b_{t-1}^{\lambda} h_{t-1}^{1-\lambda}$ and $e_{t-1}=b_{t-1} / h_{t-1}$, debt repayment is

$$
x_{t}=\frac{R_{W} b_{t-1}}{w_{t} h_{t}}=\frac{R_{W} b_{t-1}^{1-\lambda}}{w_{t} A h_{t-1}^{1-\lambda}}=\frac{R_{W}}{w_{t} A} e_{t-1}^{1-\lambda} .
$$

We can then rewrite $\omega_{1}$ and $\omega_{2}$ as

$$
\begin{aligned}
\omega_{1 t} & =\left(1-\tau-x_{t}\right) w_{t} h_{t}, \\
\omega_{2 t+1} & =\tau(1+n) w_{t+1} h_{t+1} .
\end{aligned}
$$

The pension system is a convenient assumption since then the third period income does not depend on the agent's human capital or her education choice. Thus the optimal level of education only maximizes $\omega_{1}$. Agents born in period $t-1$ choose the education investment level in order to maximize period $t$ income

$$
\max _{e_{t-1}} \omega_{1 t}=\max _{e_{t-1}} w_{t} h_{t}(1-\tau)-R_{W} b_{t-1}
$$


Using $h_{t}=A e_{t-1}^{\lambda} h_{t-1}$ and $e_{t-1}=b_{t-1} / h_{t-1}$, we have

$$
\max _{e_{t-1}} \omega_{1 t}=\max _{e_{t-1}} h_{t-1}\left((1-\tau) w_{t} A e_{t-1}^{\lambda}-R_{W} e_{t-1}\right) .
$$

The FOC gives the optimal level of investment in education

$$
e_{t-1}^{*}=\left(\frac{(1-\tau) w_{t} A \lambda}{R_{W}}\right)^{\frac{1}{1-\lambda}},
$$

and the optimal level of repayment

$$
x_{t}^{*}=\frac{R_{W}}{w_{t} A} e_{t-1}^{* 1-\lambda}=\lambda(1-\tau) .
$$

Note that the optimal repayment level only depends on pension contributions $(\tau)$ and the education externality parameter $(\lambda)$.

\subsection{Optimal decisions in a no commitment setting}

Since there is no collateral for loans, agents can choose to refund or default on credits. $^{13}$ In this no commitment setting, an endogenous constraint emerges. When adults, agents can choose to either refund or default on their education loan. If they repay, they are allowed to participate in asset markets next period and budget constraints are similar to equations (3). If they decide not to refund their credit, they are excluded from asset markets forever. That is, if they attempted to return to capital markets, their savings would be seized to pay the outstanding debt. ${ }^{14}$

This is the basic punishment mechanism. Nevertheless, we also analyze the case in which, as well as this exclusion from capital markets, agents can be punished with a proportional tax $T$ on their pension income when old. Qualitatively (see Appendix A) the key results of the model do not change. However, it is well known that models with limited commitment may generate too little debt in equilibrium. ${ }^{15}$ In our context, this translates into a high likelihood of a country falling in the constrained steady state. For this reason, in the quantitative analysis in section 6 , we introduce this pensions tax as an additional punishment. In what follows, and for simplicity, we describe the model abstracting from this tax.

\footnotetext{
${ }^{13} \mathrm{~A}$ pension system is considered in the model because a second period income is necessary to consider endogenous debt constraints. If households do not receive a retirement income, they will always pay back their loan to be able to save in middle age and thus to consume when retired.

${ }^{14}$ Note that here we do not assume only 'reputational' costs as in the early debt default literature (Eaton and Gersovitz, 1981) but also the possibility of asset seizing hence impeding any sort of smoothing through saving (Bulow and Rogoff, 1989).

${ }^{15}$ See Aguiar and Amador (2013) for an overview in the context of models of sovereign debt.
} 
Under no commitment, thus, agents cannot save and their budget constraints are

$$
\begin{aligned}
c_{t} & =w_{t} h_{t}(1-\tau) \\
d_{t+1} & =p_{t+1}
\end{aligned}
$$

The problem of the consumer born in $t-1$ is to maximize its utility (1) subject to the human capital accumulation technology (2), the budget constraints (3) and the following individual rationality constraints (IRC):

1. IRC old-age: The middle-age agents are not allowed to borrow because they would rationally never reimburse their debt when old. Hence savings should be nonnegative:

$$
s_{t} \geq 0
$$

2. IRC middle-age: The utility of repaying the debt and hence being able to save should be larger than the utility obtained from consuming only labor income in each period. This constraint can be written as:

$$
\max _{s_{t}} u\left(\omega_{1 t}-s_{t}, \omega_{2 t+1}+R_{t+1} s_{t}\right) \geq u\left(w_{t} h_{t}(1-\tau),(1+n) \tau w_{t+1} h_{t+1}\right)
$$

or combining (12) and (13) we obtain a unique IRC:

$$
\max _{s_{t} \geq 0} u\left(\omega_{1 t}-s_{t}, \omega_{2 t+1}+R_{t+1} s_{t}\right) \geq u\left(w_{t} h_{t}(1-\tau),(1+n) \tau w_{t+1} h_{t+1}\right)
$$

with $R_{t}$ observed and $R_{t+1}$ expected, $k_{t}$ is predetermined.

In this no-commitment setting, when the IRC old age holds, we know that agents have incentive to save. Nevertheless, they may have no incentive to refund their loans under IRC middle age, since the associated loss is higher than the gain from saving.

Let $V$ be the indirect utility with commitment:

$$
V\left(\omega_{1 t}, \omega_{2 t+1}, R_{t+1}\right)=\max _{s_{t}} u\left(\omega_{1 t}-s_{t}, \omega_{2 t+1}+R_{t+1} s_{t}\right),
$$

and $V^{+}$be the indirect utility considering IRC old age:

$$
V^{+}\left(\omega_{1 t}, \omega_{2 t+1}, R_{t+1}\right)=\max _{s_{t} \geq 0} u\left(\omega_{1 t}-s_{t}, \omega_{2 t+1}+R_{t+1} s_{t}\right)
$$

We first look for the upper bound on borrowing which constrains education investment, taking temporarily $R_{t-1}$ and $R_{t}$ as given. In this no-commitment setting, investors will lend only when agents are willing to refund their loans. We define the 
bound $\bar{x}$ as the one that equalizes utility when refunding and defaulting. We then obtain the effective level of saving and borrowing $(\tilde{s}$ and $\tilde{x})$ comparing the optimal and the constrained levels.

Proposition 1. Under assumption 2, if $\frac{\tau(1+n)}{(1-\tau)} \geq \mu\left(R_{t+1}\right) \frac{w_{t} h_{t}}{w_{t+1} h_{t+1}}$ then $s_{t}^{*} \leq 0$ and $\tilde{x}_{t}=\tilde{s}_{t}=0$. Otherwise, $\tilde{s}_{t}=s_{t}^{*}>0$ and $\tilde{x}_{t}=\operatorname{Min}\left(x_{t}^{*}, \bar{x}_{t}\right)$ with $\bar{x}_{t}$ the solution of

$$
\begin{gathered}
\left(R_{t+1}\left(1-\tau-\bar{x}_{t}\right) w_{t} h_{t}+\tau(1+n) w_{t+1} h_{t+1}\right) u_{2}^{\prime}\left(c_{t}, d_{t+1}\right)= \\
u\left((1-\tau) w_{t} h_{t}, \tau(1+n) w_{t+1} h_{t+1}\right)
\end{gathered}
$$

Proof: Substituting equation (7) and (8) into equation (5), we get:

$$
s_{t}^{*}=\frac{\mu\left(R_{t+1}\right)\left(1-\tau-x_{t}\right) w_{t} h_{t}-\tau(1+n) w_{t+1} h_{t+1}}{R_{t+1}+\mu\left(R_{t+1}\right)}
$$

If $x_{t}=0$ and $\frac{\tau(1+n)}{(1-\tau)} \geq \mu\left(R_{t+1}\right) \frac{w_{t} h_{t}}{w_{t+1} h_{t+1}}$, then $s_{t}^{*} \leq 0$, agents have no incentive to save even when they do not borrow. As $s_{t}^{*}$ is decreasing with $x_{t}$, we still have $s_{t}^{*} \leq 0$ when $x_{t}>0$. It follows that, under IRC old age, optimal savings are equal to zero whatever $x_{t} \geq 0$. Finally, under $\frac{\tau(1+n)}{(1-\tau)} \geq \mu\left(R_{t+1}\right) \frac{w_{t} h_{t}}{w_{t+1} h_{t+1}}$, the maximum level of borrowing is $\bar{x}=0$. If $x_{t}=0$ and $\frac{\tau(1+n)}{(1-\tau)}<\mu\left(R_{t+1}\right) \frac{w_{t} h_{t}}{w_{t+1} h_{t+1}}$, then $s_{t}^{*}>0$. Hence, there is a bound $x_{\max }>0$ such that, when $x_{t} \geq x_{\max }$, then $s_{t}^{*} \geq 0$ and thus $V^{+}=V$.

The IRC middle age gives a second upper bound $\bar{x}<x_{\max }$ above which the agent will not refund, meaning that no loan will be granted. Under IRC old-age, IRC middle age can be written as

$$
\begin{aligned}
& V^{+}\left(w_{t} h_{t}\left(1-\tau-x_{t}\right), \tau(1+n) w_{t+1} h_{t+1},\right.\left.R_{t+1}\right) \geq \\
& u\left(w_{t} h_{t}(1-\tau), \tau(1+n) w_{t+1} h_{t+1}\right) .
\end{aligned}
$$

Using the homogeneity of the utility function, $V\left(\omega_{1}, \omega_{2}, R\right)=\left(R \omega_{1}+\omega_{2}\right) u_{2}^{\prime}$, the IRC constraint (16) can be rewritten as:

$$
\begin{aligned}
&\left(R_{t+1}\left(1-\tau-x_{t}\right) w_{t} h_{t}+\tau(1+n) w_{t+1} h_{t+1}\right) u_{2}^{\prime}\left(c_{t}, d_{t+1}\right) \geq \\
& u\left(w_{t} h_{t}(1-\tau), \tau(1+n) w_{t+1} h_{t+1}\right) .
\end{aligned}
$$

We finally determine the borrowing limit $\bar{x}$ as the solution of equation (14).

We define $\Delta_{t+1}$ as the discounted wage growth rate between $t$ and $t+1$ :

$$
\Delta_{t+1} \equiv \frac{w_{t+1} h_{t+1}}{w_{t} h_{t} R_{t+1}}=\frac{k_{t+1}}{\alpha k_{t}^{\alpha}} A e_{t}^{\lambda} .
$$


The introduction of $\Delta_{t+1}$ will simplify the analytical solution of the model and allows for graphical representations.

From equation (14), the level of the threshold $\bar{x}$ depends on the pension tax parameter $\tau$. Thus, we can analyze the impact of the government choice of $\tau$ (economic policy) on households' borrowing and investment in education.

Corollary 1. The utility of default $u\left(w_{t} h_{t}(1-\tau), \tau(1+n) w_{t+1} h_{t+1}\right)$ is increasing with $\tau$ if and only if $\tau<1-\epsilon_{c}$ where $\epsilon_{c} \equiv c u_{1}^{\prime}(c, d) / u(c, d)$. The indirect utility $V^{+}\left(w_{t} h_{t}\left(1-\tau-x_{t}\right), \tau(1+n) w_{t+1} h_{t+1}, R_{t+1}\right)$ is increasing with $\tau$ if and only if $(1+$ n) $\Delta_{t+1}>1$.

Proof: The derivative of the utility of default with respect to $\tau$ is positive if and only if :

$$
w_{t} h_{t} u_{1}^{\prime}\left(w_{t} h_{t}(1-\tau), \tau(1+n) w_{t+1} h_{t+1}\right)<(1+n) u_{2}^{\prime}\left(w_{t} h_{t}(1-\tau), \tau(1+n) w_{t+1} h_{t+1}\right) .
$$

Using the homogeneity property of the utility function:

$$
\begin{array}{r}
u\left(w_{t} h_{t}(1-\tau), \tau(1+n) w_{t+1} h_{t+1}\right)=w_{t} h_{t}(1-\tau) u_{1}^{\prime}\left(w_{t} h_{t}(1-\tau), \tau(1+n) w_{t+1} h_{t+1}\right) \\
+\tau(1+n) w_{t+1} h_{t+1} u_{2}^{\prime}\left(w_{t} h_{t}(1-\tau), \tau(1+n) w_{t+1} h_{t+1}\right) .
\end{array}
$$

Inequality (18) is equivalent to $\tau<1-\epsilon_{c}$. Using the Euler equation (4), the derivative of the indirect utility with respect to $\tau$ is:

$$
\frac{d V^{+}}{d \tau}\left(c^{*}, \mu(R) d^{*}\right)=u_{1}^{\prime}\left(c^{*}, \mu(R) d^{*}\right) \frac{d c^{*}}{d \tau}+u_{2}^{\prime}\left(c^{*}, \mu(R) d^{*}\right) \mu(R) \frac{d c^{*}}{d \tau} .
$$

Which carries the sign of $d c^{*} / d \tau=\beta w_{t} h_{t}\left((1+n) \Delta_{t+1}-1\right)$.

As the utility function is homogeneous of degree one, we can compute $1-\epsilon_{c}=$ $\mu(R) /(R+\mu(R))$ which is the optimal saving rate. A change in $\tau$ will affect the middle age rationality constraint (16) in two ways.

i. In case of default, agents cannot save. Their second period income is only the pay-as-you-go pension. An increase in $\tau$ will decrease their middle age consumption and increase their old age consumption. When $\tau$ is lower than the optimal saving rate, a rise in $\tau$ makes intertemporal consumption choices closer to what the optimal choices would be (in case of access to the saving market). When $\tau$ is lower than this optimal saving rate, a rise in $\tau$ will increase the utility of default, which is the right hand side of the middle age rationality constraint (16). Thus, this rise in $\tau$ tightens the constraint. 
ii. In the case of refund, agents have access to financial markets. Thus there are two ways of transferring income from the middle age to the old age period: the pay-as-you-go pension system and saving. The condition $(1+n) \Delta_{t+1}>1$ can be rewritten $(1+n) w_{t+1} h_{t+1} / w_{t} h_{t}>R_{t+1}$, and thus means that the return from the pension system is higher than the return from private savings. In that case, when $\tau$ is raised, the utility of refund increases. The left hand side of the middle age rationality constraint (16) is higher which relaxes the constraint.

Hence, we find four cases. When $\tau<1-\epsilon_{c}$ and $(1+n) \Delta_{t+1}<1$, a rise in $\tau$ will always tighten the constraint, which means that $\bar{x}$ will decrease with $\tau$. When $\tau>1-\epsilon_{c}$ and $(1+n) \Delta_{t+1}>1, \bar{x}$ will always increase with $\tau$. Whereas when $\tau<1-\epsilon_{c}$ and $(1+n) \Delta_{t+1}>1$, or $\tau>1-\epsilon_{c}(1+n) \Delta_{t+1}>1$, the sign of the variation of $\bar{x}$ with respect to $\tau$ is ambiguous.

We now consider simple specifications of the utility and production functions, to derive explicitly the value of the bound $\bar{x}$ that determines the maximum repayment (and borrowing) allowed by international credit markets.

Assumption 4. Preferences are represented by the utility function $u\left(c_{t}, d_{t+1}\right)=$ $c_{t}^{\beta} d_{t+1}^{1-\beta}$ with $0<\beta<1$. The production function is $f\left(k_{t}\right)=k_{t}^{\alpha}$ with $\alpha \in(0,1)$.

From equation (14), considering these simple functions, we can compute explicitly $\bar{x}_{t} \equiv \bar{x}\left(\Delta_{t+1}\right)$. We obtain the following corollary:

Corollary 2. Under assumption 4, the effective loan is

$$
\begin{aligned}
\tilde{x}_{t} & =\operatorname{Min}\left(x^{*}, \bar{x}_{t}\right) \\
& =\operatorname{Min}\left(\lambda(1-\tau), 1-\tau-\eta\left(\Delta_{t+1}\right)\right),
\end{aligned}
$$

where

$$
\eta\left(\Delta_{t+1}\right)=\left(\frac{\tau(1+n)}{1-\beta}\right)^{1-\beta}\left(\frac{1-\tau}{\beta}\right)^{\beta} \Delta_{t+1}^{1-\beta}-\tau(1+n) \Delta_{t+1}
$$

When $x^{*}>\bar{x}_{t}$ agents are constrained in their education investment choice, whereas they are unconstrained when $x^{*}<\bar{x}_{t}$. Given equation (6), we also obtain the constrained education investment level:

$$
\bar{e}_{t-1}=\left(\frac{w_{t} A}{R_{W}} \bar{x}_{t}\right)^{\frac{1}{1-\lambda}}
$$




\subsection{Macroeconomic equilibrium}

Under assumption 3, agents prefer to save at home and borrow in the international market. We consider that foreign inflows of FDI and equity are policy-restricted. This allows us to model the effect of a liberalization policy that allows for increased foreign ownership in the economy's capital stock. We thus have the following assumption:

Assumption 5. Foreigners cannot hold more than a proportion $\phi \in[0,1)$ of the total domestic capital stock.

Macroeconomic equilibrium consists of:

i. The labor market equilibrium:

$$
H_{t}=N_{t-1} h_{t}
$$

ii. The asset market equilibrium:

$$
K_{t+1}=N_{t-1} s_{t}+\phi K_{t+1} \Leftrightarrow(1-\phi) K_{t+1}=N_{t-1} s_{t}
$$

Under assumptions 3 and 5, the asset market equilibrium condition equalizes the available capital stock in period $t+1$ to the amount of domestic savings in period $t$ plus the amount of foreign capital invested in the country: Since $K_{t+1}=k_{t+1} H_{t+1}$, then $(1-\phi) k_{t+1} H_{t+1}=N_{t-1} s_{t}$. Dividing by $N_{t-1} h_{t}$ we obtain:

$$
(1-\phi)(1+n) A e^{\lambda}{ }_{t} k_{t+1}=\frac{s_{t}}{h_{t}} .
$$

Under assumption 4, optimal savings from equation (5) become:

$$
\frac{s_{t}}{h_{t}}=w_{t}\left((1-\beta)\left(1-\tau-x_{t}\right)-\beta(1+n) \tau \Delta_{t+1}\right) .
$$

And we can rewrite the asset market equilibrium equation (25) as:

$$
(1-\phi)(1+n) A e_{t}^{\lambda} k_{t+1}=w_{t}\left((1-\beta)\left(1-\tau-x_{t}\right)-\beta(1+n) \tau \Delta_{t+1}\right) .
$$

Since equation (17) implies that

$$
\Delta_{t+1}=\frac{A e_{t}^{\lambda}}{w_{t}} \frac{1-\alpha}{\alpha} k_{t+1}
$$

the equilibrium equation is finally:

$$
(1+n) \Delta_{t+1}\left((1-\phi) \frac{\alpha}{1-\alpha}+\beta \tau\right)=(1-\beta)\left(1-\tau-x_{t}\right) .
$$




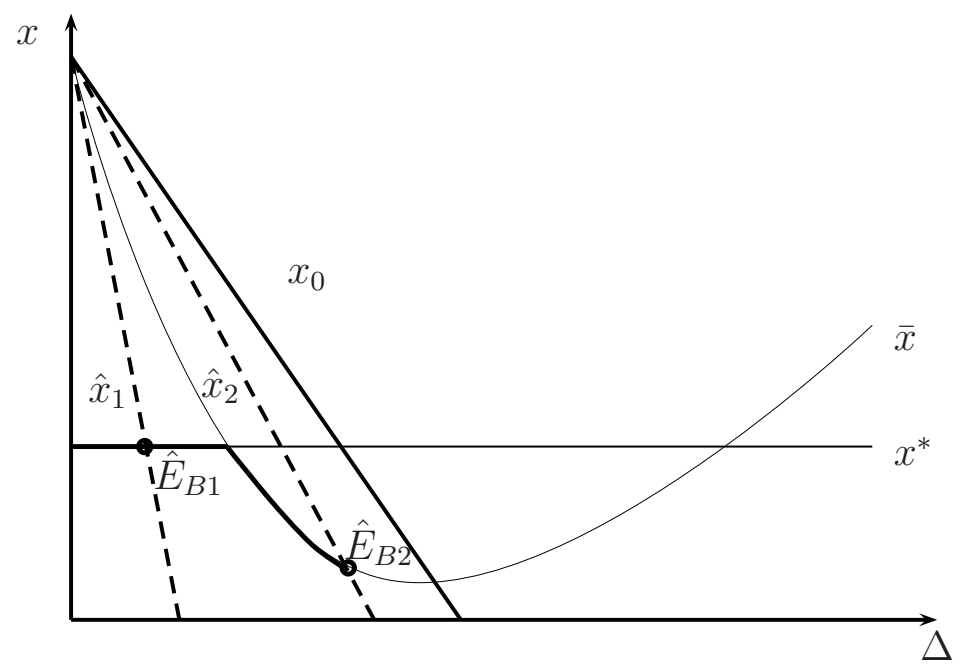

Figure 2: The Dark curve represents effective $x$ (optimal under the IRC constrainst). Case 1 (resp. Case 2) gives the equilibrium $\hat{E}_{B 1}$ (resp. $\hat{E}_{B 2}$ ) when market clearing conditions are represented by curve $\hat{x}_{1}(\Delta)$ (resp. curve $\hat{x}_{2}(\Delta)$ ).

If we denote by $\hat{x}$ the equilibrium debt repayment, then:

$$
\hat{x}_{t} \equiv \hat{x}_{t}\left(\Delta_{t+1}\right)=1-\tau-\left((1-\phi) \frac{\alpha}{1-\alpha}+\beta \tau\right) \frac{(1+n)}{1-\beta} \Delta_{t+1} .
$$

An equilibrium is an intertemporal sequence $\left(k_{t}, x_{t}\right)_{t=0}^{+\infty}$ which solves the firm's and the consumer's programs, and such that markets clear. Thus, a perfect foresight equilibrium is defined by $\Delta_{t+1}$ such that in period $t$ the effective optimal choice considering the constraint $\tilde{x}$, from equation (21), is equal to the equilibrium value $\hat{x}$, from equation (30). Since from these equations $\tilde{x}_{t}$ and $\hat{x}_{t}$ are functions of $\Delta_{t+1}$ for all $t \geq 0$ and intersect only once, then for a given economy, there exists a unique value of $\Delta_{t+1}=\Delta$ corresponding to the equilibrium. The equilibrium discounted wage growth rate $\Delta$ is characterized by a set of parameters, and is constant whatever the initial condition $k_{0}$ (see next section). Nevertheless, capital intensity $k_{t}$ will dynamically adjust from this initial condition $k_{0}$. Figure 2 depicts the equilibrium, which can either be unconstrained $\left(\hat{E}_{B 1}\right)$ or constrained $\left(\hat{E}_{B 2}\right)$. For instance, the unconstrained equilibrium would correspond to an economy $B_{1}$ whose public pensions system size, $\tau$, is small whereas the constrained one would correspond to an economy $B_{2}$ where $\tau$ is high. A policy decreasing $\tau$ may change the equilibrium from constrained to unconstrained. Likewise, other relevant parameter changes, including the degree of openness $\phi$ and the savings rate (determined by $\beta$ ), can affect the equilibrium towards 
which the economy converges. ${ }^{16}$

\section{Equilibrium dynamics}

Proposition 2. For any initial condition $k_{0}>0$, an economy where $0<\phi<1$ converges to a unique steady state equilibrium. But depending on parameter values, two configurations can occur:

i. If $\beta(1-\lambda) \geq\left(\frac{\tau(1-\alpha)}{(1-\phi) \alpha-\tau(1-\alpha)}\right)^{\frac{1-\beta}{\beta}}$, the economy is unconstrained and the steady state is $k_{u}=\Omega_{u}^{\frac{1-\lambda}{\alpha \lambda+(1-\lambda)(1-\alpha)}} R_{W}^{\frac{\lambda}{\alpha \lambda+(1-\lambda)(1-\alpha)}}$ with

$$
\Omega_{u} \equiv \frac{\alpha(1-\tau)(1-\lambda) Q}{A^{\frac{1}{1-\lambda}}((1-\alpha) \lambda(1-\tau))^{\frac{\lambda}{1-\lambda}}},
$$

and

$$
Q \equiv \frac{1-\beta}{(1+n)\left((1-\phi) \frac{\alpha}{1-\alpha}+\beta \tau\right)}
$$

ii. If $\beta(1-\lambda)<\left(\frac{\tau(1-\alpha)}{(1-\phi) \alpha-\tau(1-\alpha)}\right)^{\frac{1-\beta}{\beta}}$, the economy is constrained and the steady state is $k_{c}=\Omega_{c}^{\frac{1-\lambda}{\alpha \lambda+(1-\lambda)(1-\alpha)}} R_{W}^{\frac{\lambda}{\alpha \lambda+(1-\lambda)(1-\alpha)}}$ with

$$
\Omega_{c} \equiv \frac{\alpha \Delta_{c}}{A^{\frac{1}{1-\lambda}}\left((1-\alpha)\left(1-\tau-\frac{\Delta_{c}}{Q}\right)\right)^{\frac{\lambda}{1-\lambda}}} .
$$

Proof: See Appendix B.

The analysis of the model's dynamics implies that, whatever the initial condition $k_{0}$, the economy will converge monotonically to the long run steady state. This steady state is unconstrained if the parameters are such that $\beta(1-\lambda) \geq\left(\frac{\tau(1-\alpha)}{(1-\phi) \alpha-\tau(1-\alpha)}\right)^{\frac{1-\beta}{\beta}}$, and constrained if $\beta(1-\lambda)<\left(\frac{\tau(1-\alpha)}{(1-\phi) \alpha-\tau(1-\alpha)}\right)^{\frac{1-\beta}{\beta}}$. Moreover, if parameters change (a rise in $\phi$ for example) such that the economy moves from one regime to the other, the economy just jumps to the new equilibrium path converging monotonically to the new steady state.

\footnotetext{
${ }^{16}$ In the case of a pension system depending on the agent's own human capital, agents would have an additional incentive to invest in education. This might increase the level of education and could also potentially change the equilibrium from constrained to unconstrained.
} 


\section{Capital inflows and economic growth}

The model describes an economy which can either be constrained or unconstrained depending on parameters such as the size of the public pension $(\tau)$, population growth $(n)$, time preference $(\beta)$ and, finally, the degree of financial openness $\phi$. We focus here on the effect of capital flows on growth through parameter $\phi$.

Proposition 3. Financial openness and equilibrium.

Under assumptions 3, 4, and 5, there is a unique value $\bar{\phi}$ such that the borrowing constraint is active if and only if $\phi>\bar{\phi}$ with $\bar{\phi}>0$ for $\lambda<\bar{\lambda}_{\max }=$ $1-\frac{(\alpha+\beta \tau(1-\alpha))}{\beta(1-\alpha)}\left(\frac{1-\alpha}{\tau(1-\alpha)+\alpha}\right)^{\frac{1}{\beta}} \tau^{\frac{1-\beta}{\beta}}$. The bound $\bar{\phi}$ is decreasing with the pension tax $\tau$.

Proof: See Appendix C.

Proposition 3 defines a threshold for financial openness $\bar{\phi}$ below (above) which an economy is unconstrained (constrained) whatever the initial condition $k_{0}$. Another look at figure 2 illustrates the situation of country $B$. Initially, economy $B$ is unconstrained and the equilibrium is $\hat{E}_{B 1}$. An increase in openness rotates the equilibrium doted line anti-clockwise and the new equilibrium is $\hat{E}_{B 2}$. In this new equilibrium, economy $B$ is constrained. The calibration section provides some examples of countries which may behave as country B. Since when the pension tax $\tau$ increases the incentive to repay the educational loan decreases, the bound $\bar{\phi}$ is decreasing with $\tau$.

In our framework, the growth rate is given by the rate of growth of human capital:

$$
\frac{h_{t+1}}{h_{t}}=A b_{t}^{\lambda} h_{t}^{-\lambda}=A e_{t}^{\lambda} .
$$

Proposition 4. Financial openness and balanced growth path.

Under assumptions 3, 4 and 5, if $\phi \leq \bar{\phi}$ the economy is unconstrained, and if $\phi>\bar{\phi}$ the economy is constrained. Let $\varepsilon$ denote an increase in financial openness such that, initially, financial openness is $\phi$ and becomes $\phi+\varepsilon$ with liberalization.

$i$. When the economy is initially constrained $(\phi>\bar{\phi})$, the growth rate is decreasing with openness.

ii. When the economy is initially unconstrained $(\phi<\bar{\phi})$ and remains unconstrained $(\phi+\varepsilon<\bar{\phi})$, the growth rate is increasing with openness.

iii. When the economy is initially unconstrained $(\phi<\bar{\phi})$ and becomes constrained with openness $(\phi+\varepsilon>\bar{\phi})$, the growth rate is first increasing and then decreasing with openness, with a maximum at $\bar{\phi}$. 
Proof: See Appendix D.
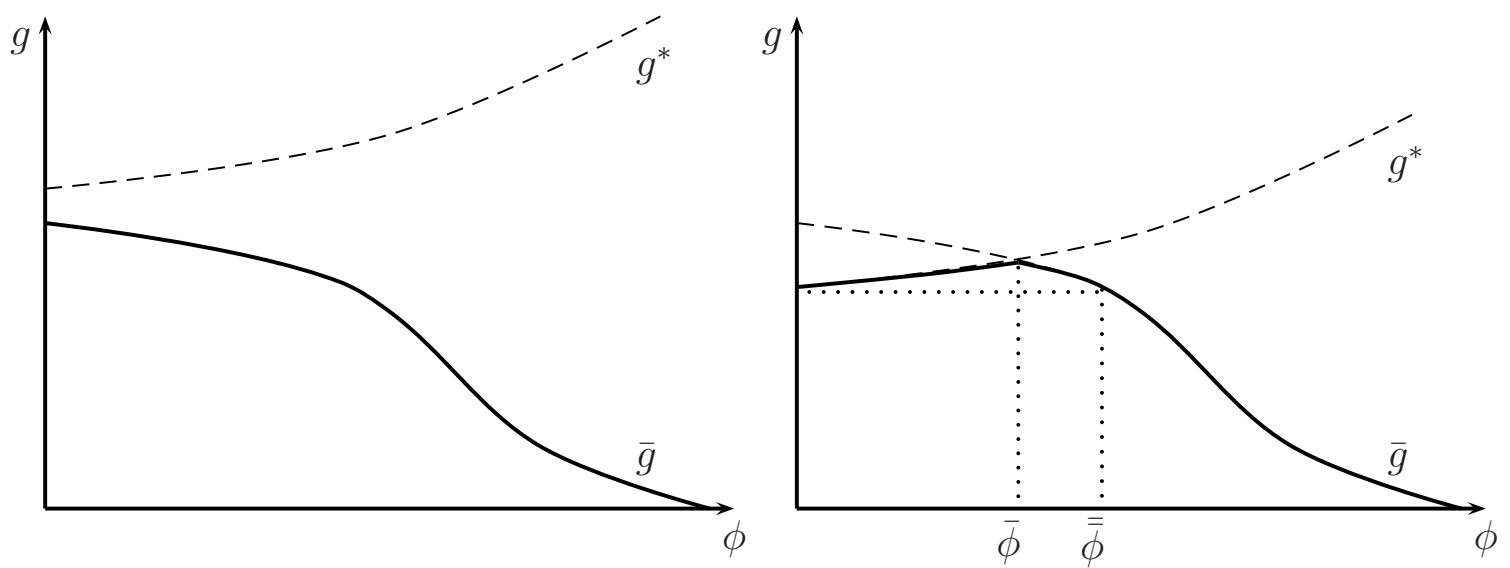

Figure 3: Openness and growth: the figure graphs growth $g$ against openness $\phi$, where $\bar{\phi}$ and $\overline{\bar{\phi}}$ are the two thresholds defined in the main text. It illustrates two configurations, a constrained economy $\left(\bar{g}<g^{*}\right)$ and an unconstrained economy when $\phi<\bar{\phi}\left(g^{*}<\bar{g}\right)$.

The intuition behind this proposition 4 is as follows. An increase in openness mechanically rises the stock of capital and thus increases the wage and decreases the domestic interest rate. The way these changes affect the economy depends on the steady state. In Figure 3, the left panel corresponds to the case where an initially constrained economy remains constrained whatever $\phi \in(0,1)$. The interest rate drop reduces agents' incentives to save and to refund their loan when adult (interest rate effect). Agents become endogenously more constrained and, hence, education spending decreases. This means that, for an initially constrained economy, openness is bad for growth. The second right panel corresponds to the case where an initially unconstrained economy may become constrained with openness: $\phi<\bar{\phi}$ but $\phi+\varepsilon>\bar{\phi}$. As long as $\phi \leq \bar{\phi}$, the economy remains unconstrained and then the rise in $w$ increases the incentive to invest in human capital (wage effect). Agents are unconstrained and can reach this higher level of education. This means that, in an initially unconstrained economy, a moderate increase in capital inflows is good for growth. Conversely, if $\phi+\varepsilon>\bar{\phi}$, the interest rate effect dominates and the growth rate starts decreasing with openness. Nevertheless, the growth rate of the open economy still exceeds the almost closed economy one as long as $\phi+\varepsilon<\overline{\bar{\phi}}$ with $\overline{\bar{\phi}}$ such that, if we denote constrained and unconstrained growth respectively as functions of financial openness $\bar{g} \equiv \bar{g}(\phi)$ and $g^{*}=g^{*}(\phi)$, we have $\bar{g}(\overline{\bar{\phi}})=\lim _{\phi \rightarrow 0} g^{*}(\phi)$. Above this threshold $\overline{\bar{\phi}}$, openness has a global negative effect on growth. 
To summarize, in the model, financial openness is bad for growth if the economy is initially constrained, or if openness becomes too large $(\phi+\varepsilon>\overline{\bar{\phi}})$. This is because, for given values of $\tau, \beta, \lambda$, and $n$, the larger the capital inflows, the stronger is the interest rate effect and hence the incentive to default which constrains access to international credit markets. The question is then, what the role of savings and policy variables is in determining the success of liberalization policies. We address this question with a quantitative exercise.

\section{Quantitative analysis}

We present a quantitative exercise in order to assess how likely the constrained steady state is to happen for a series of selected countries. We also address a policy question: what would be the savings rate and/or public pension contributions required to move the economy from the constrained to the unconstrained steady state? Finally, we address quantitatively the growth gains of capital flows under both equilibria. We calibrate the model using data on seven countries. These have been selected in terms of their relevance to the theory model. They include Latin American countries as well as Southern European countries. The selection is, however, limited due to data availability.

The parameters of the model are calibrated using data from different sources. Table 2 collects parameter values. We consider a generation to last 25 years. Population growth $n$ is the rate of growth of working age population obtained from the World Development Indicators (WDI). To measure $\tau$, we use pension outlays as a percentage of GDP from OECD statistics and OECD Pensions at a Glance (2009) and divide it through by one minus the capital share to obtain $\tau$ as pension outlays as a percentage of wage income. Capital shares, $\alpha$, are given in Caselli (2005), except for Brazil which is given by Gomes et al. (2005). Parameter $\phi$ is the stock of FDI and equity investment as a percentage of GDP (average for 1970-2007) from Lane and Milesi-Ferreti (2007). This is then transformed into a percentage of capital stock using the capital-labor ratio from Caselli (2005). We calculate the marginal product of capital $R$ as $\alpha Y / K$, where $Y / K$ is obtained as the average output to capital ratio for the 1950-2011 period from the Penn World Tables (PWT). To calibrate the rate of time preference, namely $\beta$, we consider data on private savings rates (from WDI, Eurostat and OECD), the marginal product of capital $(R)$, working age population growth $n$, and output growth (from WDI). From the model, savings are given by

$$
s_{t}=\left[w_{t} h_{t}-\bar{R} b_{t-1}\right](1-\beta)-\beta \tau(1+n) \frac{w_{t+1} h_{t+1}}{R_{t+1}}
$$

Along the steady path, we have $k_{t+1}=k_{t}=k$, then $w_{t+1}=w_{t}=w$ and the saving 
rate is

$$
\frac{s}{w h} \simeq(1-\beta)-\beta \tau(1+n)(1+g) \frac{1}{R}
$$

Given $R, g, \tau$ and $n$ we compute $\beta$ from equation (35). ${ }^{17}$ Finally, education productivity $A$ is calibrated so as to match the rate of growth of per capita GDP for these economies in the pre-liberalization period. For most countries, where available, and where not indicated otherwise, we used data from 1970 to 2010.

Table 2: Parameters calibration. Annualized rates.

\begin{tabular}{lcccccc} 
& $n$ & $\tau$ & $\alpha$ & $\phi$ & $R$ & $\beta$ \\
\hline Brazil & 0.047 & 0.1066 & 0.25 & 0.075 & 0.070335 & 0.6855 \\
Chile & 0.035 & 0.0476 & 0.16 & 0.25 & 0.072643 & 0.6967 \\
Colombia & 0.055 & 0.0568 & 0.12 & 0.017 & 0.038423 & 0.6939 \\
Greece & 0.008 & 0.1188 & 0.15 & 0.04 & 0.05132 & 0.7427 \\
Italy & 0.004 & 0.1341 & 0.21 & 0.045 & 0.063015 & 0.6770 \\
Mexico & 0.054 & 0.0093 & 0.25 & 0.077 & 0.108584 & 0.6908 \\
Spain & 0.012 & 0.1013 & 0.24 & 0.08 & 0.088658 & 0.7040 \\
\hline
\end{tabular}

Parameter $\lambda$ represents the contribution of private education spending to human capital accumulation. This elasticity is crucial to determine whether a country converges to the constrained or the unconstrained steady state since it determines the private returns to investment in human capital. However, there is no direct observable measure for this parameter. Accordingly, we use a range of values for $\lambda$ for all countries proxied from cross-country estimates. In order to obtain plausible values for $\lambda$, we estimate $(1-\lambda)$ as the degree of inter-generational education persistence for a cross-section of close to 150 countries. This is, no doubt, an imperfect measure. But we take these only as reference for a range of calibrated values. Based on the human capital accumulation equation (2), we estimate:

$$
\ln h_{i, t}=\ln A+(1-\lambda) \ln h_{i, t-25}+X_{i, t}^{\prime} \chi+\varepsilon_{i, t} .
$$

Here, $h_{i, t}$ is the average number of years of education of population aged 15 years or more for country $i$ at time $t$, where we use three different reference periods $t=2000,2005,2010$. Variable $h_{i, t-25}$ is the average number of years of education a generation earlier, i.e. 25 years earlier, such that $t-25=1975,1980,1985 . X^{\prime}$ is a vector of control variables to proxy for investment in education, and $\chi$ is a vector of parameters to estimate. The control variables include public and private (where

\footnotetext{
${ }^{17}$ Note that we observe the savings rate from the data. For calibration, we transform these as savings as a percentage of wage income dividing them by the labor share $(1-\alpha)$.
} 
available) spending in education, pupil to teacher ratios, PCs per 100 people, and internet users per 100 people as proxies for education effort. All data come from the World Bank Education Statistics. In some specifications, we also measured $h_{i, t}$ the average number of years of education of population aged 25 years or more. We experimented with a large number of specifications using different dependent variables and combinations of control variables that differed greatly in terms of the sample of countries considered. ${ }^{18}$ The great majority of the estimates of $\lambda$ fell in the range of 0.3 to 0.6 . Given these estimates, we carry out the calibration below using values for $\lambda=0.35,0.45,0.55 .^{19}$

Using Proposition 2, we can compute the threshold $\bar{\phi}$. To determine whether a country is constrained or not in the long run we compare this threshold with the observed $\phi$. As discussed in Section 3 and Appendix A, the punishment based on exclusion from capital markets is usually too small to generate enough incentives to refund the educational loan. We thus introduce a proportional tax on pensions income under no commitment. This tax increases incentives to reimburse the loan by reducing expected pensions income in case of default. We used alternative values for this proportional tax. The results presented below are for a tax of $30 \%$ (i.e. $T=0.3$ ).

For each country, Table 3 collects the different values of $\bar{\phi}$ (for the three values of $\lambda$ ) and the last column gives the observed value of $\phi$. Comparing $\phi$ and $\bar{\phi}$, we can sort the countries in three groups. Colombia, Greece, and Italy belong to the group of countries that are always constrained even with the low boundary for $\lambda$. Mexico is the only country that is always unconstrained regardless of $\lambda$. The other countries may be in a constrained or unconstrained equilibrium depending on $\lambda$. Table 3 also reports $\overline{\bar{\phi}}$ for which increased capital inflows would have a globally negative growth effect. ${ }^{20}$ None of the countries exceed this threshold.

Given the importance of the savings rate and the policy parameter $\tau$, we can calculate what would be the implied savings rate and/or pension contribution that would ensure convergence to an unconstrained steady state. Keeping all parameters fixed, we determine successively the threshold in $\beta$ (or, alternatively, the saving rate) and the threshold in $\tau$. Table 4 collects these thresholds for two values of parameter $\lambda .^{21}$ For most countries, when $\lambda=0.45$, the required savings rate is well above $1 / 4$

\footnotetext{
${ }^{18}$ Results are available on request.

${ }^{19} \mathrm{An}$ alternative approximation of $\lambda$ can be obtained from the fact that Mincerian equation estimates typically yield wage gains of an extra year of education of around $10 \%$. It can easily be shown that, in our model, this semi-elasticity is given by $\frac{\partial\left(w_{t} h_{t}\right) /\left(w_{t} h_{t}\right)}{\partial b_{t-1}}=\lambda \frac{1}{b_{t-1}}$. If we consider data for the cross section of countries used in estimation, years of education 25 years ago in 1975, 1980 and 1985 are, on average, 4.3, 4.8 and 5.4. If we normalize the cost of one year of education to one, this yields $\lambda$ values between 0.43 and 0.54 , which are well within the range of estimated values.

${ }^{20}$ This is only calculated for countries that can be in either steady state.

${ }^{21}$ For $\lambda=0.55$, the required savings rate would be higher and the required $\tau$ lower than in the two cases presented in the table.
} 
Table 3: Calibrated $\bar{\phi}$ and $\overline{\bar{\phi}}$ and observed $\phi(T=0.3)$.

\begin{tabular}{|c|c|c|c|c|c|}
\hline & \multicolumn{3}{|c|}{$\bar{\phi}$} & $\overline{\bar{\phi}}$ & $\phi$ \\
\hline & $\lambda=0.35$ & $\lambda=0.45$ & $\lambda=0.55$ & & \\
\hline Brazil & 0.2729 & -0.3157 & -1.3563 & 1.0807 & 0.075 \\
\hline Chile & 0.3729 & -0.1432 & -1.0781 & 1.0940 & 0.25 \\
\hline Colombia & -0.0192 & -0.8545 & -2.3578 & & 0.017 \\
\hline Greece & -1.6300 & -4.0474 & -8.9710 & & 0.04 \\
\hline Italy & -0.0641 & -0.9170 & -2.3986 & & 0.045 \\
\hline Mexico & 0.9335 & 0.8793 & 0.7825 & & 0.077 \\
\hline Spain & 0.1233 & -0.6107 & -1.9686 & 1.0911 & 0.08 \\
\hline
\end{tabular}

of GDP. In the case of Greece, this ratio is $33 \%$ for $\lambda=0.45$, which is almost twice its average savings rate since 1970. Likewise, the implied $\tau$ threshold would require a dramatic reduction of the public pensions outlays as a percentage of wage income for most countries, especially for Greece, Italy, Spain, and Brazil.

Table 4: Threshold values of $\beta$, savings rate and $\tau$ to benefit from capital inflows

$$
(T=0.3) \text {. }
$$

\begin{tabular}{lccc|ccc} 
& \multicolumn{3}{c}{$\lambda=0.35$} & \multicolumn{3}{c}{$\lambda=0.45$} \\
\hline Brazil & $\beta$ & $s$ & $\tau$ & $\beta$ & $s$ & $\tau$ \\
Chile & 0.7120 & 0.1683 & 0.1545 & 0.6461 & 0.2221 & 0.0431 \\
Colombia & 0.6898 & 0.1940 & 0.1493 & 0.6219 & 0.2615 & 0.3286 \\
Greece & 0.6379 & 0.2754 & 0.0254 & 0.5666 & 0.3397 & 0.0112 \\
Italy & 0.6645 & 0.2403 & 0.0917 & 0.5947 & 0.2980 & 0.0444 \\
Mexico & 0.8827 & 0.0861 & 0.1435 & 0.8451 & 0.1144 & 0.0641 \\
Spain & 0.7112 & 0.2059 & 0.0815 & 0.6452 & 0.2573 & 0.0403 \\
\hline
\end{tabular}

Finally, we calibrate the effects of capital inflows on economic growth. The exercise we consider is as follows. Taking the threshold $\bar{\phi}$ for which openness reduces growth, we calculate the effect of a $150 \%$ increase in openness $\phi$ below and above the threshold. That is, we consider the effects of capital inflows on growth in the unconstrained (positive) and constrained (negative) steady states around the $\bar{\phi}$ threshold. For example, Brazil experienced a per capita growth rate of 3.02 per year before liberalization. When $\phi$ rises from 0.18 to 0.27 , in the unconstrained steady state, Brazil's growth rate increases to 3.08 per year. In the constrained steady state, when $\phi$ increases from 0.27 to 0.41 , growth falls from 3.02 to 2.84 . 
Table 5 presents the results in terms of annualized growth rate changes. We show the effects for the unconstrained steady state only for those four countries that can fall in the unconstrained steady state. The effects on growth in the constrained steady state are shown for all countries except Mexico, which is always unconstrained. The quantitative effects of the liberalization policy in the unconstrained steady state are small. The growth gains in the unconstrained steady state average $0.04 \%$ per year, and are as small as $0.02 \%$ per year for Spain. These small gains are consistent with the insignificant effects found in some empirical estimates. The negative growth effects in the constrained steady state are slightly more sizeable although never very large. The largest negative effect, corresponding to Chile, would imply a growth loss of $0.2 \%$ per year. For the rest of the countries, however, the growth effect is less than $-0.07 \%$ per year on average.

Table 5: Growth (annualized) effects of a 150\% increase in $\phi . \lambda=0.35, T=0.3$.

Unconstrained Steady State

\begin{tabular}{lcccc}
\hline & Initial $\phi$ & Final $\phi$ & Growth before & Growth after \\
\hline Brazil & 0.1818 & 0.2728 & 3.0259 & 3.0834 \\
Chile & 0.2485 & 0.3728 & 4.9051 & 4.9614 \\
Mexico & 0.077 & 0.1155 & 3.6845 & 3.7108 \\
Spain & 0.0821 & 0.1232 & 2.2358 & 2.2573 \\
\hline \multicolumn{5}{c}{ Constrained Steady State } \\
\hline Brazil & Initial $\phi$ & Final $\phi$ & Growth before & Growth after \\
Chile & 0.273 & 0.4095 & 3.0259 & 2.8357 \\
Colombia & 0.373 & 0.5595 & 4.9051 & 4.7036 \\
Greece & 0.017 & 0.0255 & 3.4390 & 3.4331 \\
Italy & 0.045 & 0.060 & 2.3044 & 2.2898 \\
Spain & 0.1234 & 0.1851 & 2.2358 & 2.4019 \\
\hline
\end{tabular}

\section{Conclusion}

The effect of capital inflows on growth has met with empirically mixed results. However, the observation that current account surplus countries tend to grow faster than current account deficit countries, has led to the development of a large literature that analyzes the correlation between growth and capital flows for surplus economies such as China, mostly in the context of exogenous growth models. This correlation, however, also appears to hold for deficit countries. Successful capital account 
liberalizations also tend to be associated with higher savings rates.

In order to understand the relationship between growth and capital flows for deficit countries, we develop an OLG model of endogenous growth and credit constraints for economies whose autarky interest rate is above the world interest rate. Compatible with existing evidence, capital inflows may either benefit or harm growth. The model features endogenous growth through the accumulation of productive knowledge (human capital). It also contains physical capital and a pay-as-you-go pensions system that ensure a unique equilibrium. Importantly, since human capital is not collateralizable, access to international credit markets is endogenously determined. The model features a unique equilibrium, which can either be constrained or unconstrained. Then countries can converge to a constrained or an unconstrained steady state.

In a constrained economy, because of default incentives, opening up to capital inflows is bad for growth because it tightens credit constraints. Interest rates fall and the return on savings falls giving agents less incentives to participate in asset markets and hence more incentives to default on education investment loans. Thus, they decrease savings and the accumulation of human capital having a negative effect on growth. Results are reversed in an unconstrained economy in which capital inflows become growth enhancing since agents can reach their optimal human capital level. We study the effects of changes in some of the key parameters of the model to understand the threshold nature of the capital flows-economic growth nexus. Focusing on the effect of openness to FDI and equity inflows, we carry out a quantitative exercise analyzing the likelihood of a set of economies falling in either steady state and the required savings rate and public pensions size that would make these economies unconstrained. We also analyze the growth effects of increased capital inflows and find them to be quantitatively small.

Our results can be used to understand a body of recent empirical evidence finding negative effects of capital flows on growth for poor and low savings economies. Potential extensions of the model could consider the role of non-tradable sectors and the real exchange rate. Since non-traded goods cannot be used to smooth consumption intertemporally, changes in the real exchange rate can affect the endogenous constraint and hence lead to a relationship between (persistent) real exchange rate changes and growth. 


\section{Appendices}

\section{A Equilibrium with a tax punishment on pension income.}

For calibration, we introduce a proportional tax on retirement pensions $T>0$ as an additional punishment. In case of default, agents are not only excluded from the asset markets, but also taxed on their pension. In this case, the budget constraints remain unchanged under commitment. However, without commitment they become

$$
\begin{aligned}
c_{t} & =w_{t} h_{t}(1-\tau) \\
d_{t+1} & =p_{t+1}(1-T)
\end{aligned}
$$

We then have that $x \max \left(s^{*}=0\right)$ does not change, but $\bar{x}$ now satisfies

$$
\begin{gathered}
(1-\beta)\left[R_{t+1}\left(1-\tau-\bar{x}_{t}\right) w_{t} h_{t}+\tau(1+n) w_{t+1} h_{t+1}\right]\left(\frac{c_{t}}{d_{t+1}}\right)^{\beta} \\
=\left[w_{t} h_{t}(1-\tau)\right]^{\beta}\left[\tau(1+n) w_{t} h_{t}(1-T)\right]^{1-\beta}
\end{gathered}
$$

which yields, as before

$$
\tilde{x}_{t}=\operatorname{Min}\left(x^{*}, \bar{x}_{t}\right)=\operatorname{Min}\left(\lambda(1-\tau), 1-\tau-\eta\left(\Delta_{t+1}\right)\right) .
$$

With the presence of $T$ in $\eta$

$$
\eta\left(\Delta_{t+1}\right)=\left(\frac{\tau(1+n)(1-T)}{1-\beta}\right)^{1-\beta}\left(\frac{1-\tau}{\beta}\right)^{\beta}-\tau(1+n) \Delta_{t+1} .
$$

Then, the macroeconomic equilibrium is unchanged and, introducing $T$, the only relationsips affected are

$$
\Delta_{c}=\left(\frac{\left(\frac{\tau(1+n)(1-T)}{1-\beta}\right)^{1-\beta}\left(\frac{1-\tau}{\beta}\right)^{\beta} Q}{1+\tau(1+n) Q}\right)^{\frac{1}{\beta}}
$$

and

$$
\bar{\Delta}=[\tau(1-T)]^{\frac{1-\beta}{\beta}} \frac{(1-\beta)(1-\tau)}{(1+n) \beta}\left(\frac{1-\alpha}{(1-\phi) \alpha+\tau(1-\alpha)}\right)^{\frac{1}{\beta}}
$$

We then obtain $\bar{\phi}$ as a solution to $\bar{\Delta}=\Delta^{*}$

$$
[\tau(1-T)]^{\frac{1-\beta}{\beta}} \frac{1}{\beta}\left(\frac{1-\alpha}{(1-\bar{\phi}) \alpha+\tau(1-\alpha)}\right)^{\frac{1}{\beta}}=\frac{(1-\lambda)(1-\alpha)}{(1-\bar{\phi}) \alpha+\beta \tau(1-\alpha)} .
$$


Intuitively, a stronger punishment makes the country less likely to be constrained (higher $\bar{\phi}$ ). The punishment does not affect the optimal level of education but gives stronger incentives in favor of refunding and increases the amount the country can borrow.

\section{B Proof of Proposition 2}

Lemma 1. Whatever the parameters configuration, the dynamics of the model can be summarized by the dynamic equation

$$
\Omega_{i} k_{t}^{\alpha}=k_{t+1}^{\frac{1-\lambda+\alpha \lambda}{1-\lambda}} R_{W^{\frac{-\lambda}{1-\lambda}}}
$$

With $\Omega_{i}>0, i=u, c$, for $u$ unconstrained and c constrained.

Proof. Considering equations (6) and (17) which give the definitions of debt repayment $x$ and the wage growth rate $\Delta$, we obtain a first dynamic equation linking $x, \Delta$ and $k$ :

$$
\alpha \Delta_{t+1} k_{t}^{\alpha}=A^{\frac{1}{1-\lambda}} k_{t+1}^{\frac{1-\lambda+\alpha \lambda}{1-\lambda}}\left(\frac{(1-\alpha) x_{t+1}}{R_{W}}\right)^{\frac{\lambda}{1-\lambda}}
$$

The asset market equilibrium equation (29) gives a relationship between $\Delta$ and $\hat{x}$ :

$$
\Delta_{t+1}=\left(1-\tau-\hat{x}_{t}\right) Q
$$

Substituting $\Delta$ from equation (39) into equation (38), we get:

$$
\alpha k_{t}^{\alpha}\left(1-\tau-\hat{x}_{t}\right) Q=A^{\frac{1}{1-\lambda}} k_{t+1}^{\frac{1-\lambda+\alpha \lambda}{1-\lambda}}\left(\frac{(1-\alpha) \hat{x}_{t+1}}{R_{W}}\right)^{\frac{\lambda}{1-\lambda}}
$$

Consider firstly the unconstrained case where $\hat{x}_{t}=x^{*}=\lambda(1-\tau)$. Equation (40) can be rewritten:

$$
\Omega_{u} k_{t}^{\alpha}=k_{t+1}^{\frac{1-\lambda+\alpha \lambda}{1-\lambda}} R_{W}^{\frac{-\lambda}{1-\lambda}}
$$

with

$$
\Omega_{u} \equiv \frac{\alpha(1-\tau)(1-\lambda) Q}{A^{\frac{1}{1-\lambda}}((1-\alpha) \lambda(1-\tau))^{\frac{\lambda}{1-\lambda}}} .
$$

Consider secondly the constrained case where $\hat{x}_{t}=\bar{x}=1-\tau-\eta\left(\Delta_{t+1}\right)$. From equation (39) we obtain

$$
\Delta_{t+1}=\Delta_{c}=\left(\frac{\left(\frac{\tau(1+n)}{1-\beta}\right)^{1-\beta}\left(\frac{1-\tau}{\beta}\right)^{\beta} Q}{1+\tau(1+n) Q}\right)^{\frac{1}{\beta}}
$$


Substituting into equation (39) we get:

$$
\Omega_{c} k_{t}^{\alpha}=k_{t+1}^{\frac{1-\lambda+\alpha \lambda}{1-\lambda}} R_{W}^{\frac{-\lambda}{1-\lambda}}
$$

with

$$
\Omega_{c} \equiv \frac{\alpha \Delta_{c}}{A^{\frac{1}{1-\lambda}}\left((1-\alpha)\left(1-\tau-\frac{\Delta_{c}}{Q}\right)\right)^{\frac{\lambda}{1-\lambda}}}
$$

which yields (37).

We consider that $0<\phi<1$ and agents can borrow at the international interest rate, namely $R_{W}$. Then equation (37) becomes:

$$
k_{t+1}=\Omega_{i}^{\frac{1-\lambda}{1-\lambda+\alpha \lambda}} R_{W}^{\frac{\lambda}{1-\lambda+\alpha \lambda}} k_{t}^{\frac{\alpha(1-\lambda)}{1-\lambda+\alpha \lambda}} .
$$

Again there are two steady state equilibria, the trivial one $k=0$, and $\tilde{\tilde{k}}_{i}=$ $\Omega_{i}^{\frac{1-\lambda}{\alpha \lambda+(1-\lambda)(1-\alpha)}} R_{W}^{\frac{\lambda}{\alpha \lambda+(1-\lambda)(1-\alpha)}}$. And for a given initial condition $k_{0}$, the economy will converge monotonically to the steady state $\tilde{\tilde{k}}_{i}$.

\section{Proof of Proposition 3}

From equation (26), the condition $s_{t}>0$ can be rewritten as $x_{t}<x_{0}\left(\Delta_{t+1}\right)$ with:

$$
x_{0}\left(\Delta_{t+1}\right) \equiv 1-\tau-\frac{\beta}{1-\beta} \tau(1+n) \Delta_{t+1} .
$$

Then, from equations (47) and (30), the equilibrium is always such as the condition $s>0$ holds.

Moreover, $x^{*}$ is constant and $\bar{x}$ is convex, first decreasing and then increasing. As $\bar{x}(0)=1-\tau$ and $x^{*}=\lambda(1-\tau)$, then $x^{*} \leq \bar{x}(0)$.

Let us denote $\Delta_{0}$ the value of $\Delta$ such that $x^{*}$ corresponds to $s_{t}=0$. If $\bar{x}\left(\Delta_{0}\right)<x^{*}$, then there exists a unique value $\Delta_{1}$ such that when $\Delta<\Delta_{1}, \bar{x}(\Delta)>x^{*}$, and when $\Delta>\Delta_{1}, \bar{x}(\Delta)<x^{*}$. This is illustrated by Figure 4 .

From equation (47), $x^{*}=x_{0}(\Delta)$ for $\Delta=\Delta_{0}$ with

$$
\Delta_{0}=\frac{(1-\beta)(1-\tau)(1-\lambda)}{\beta \tau(1+n)},
$$

and the value of $\bar{x}$ corresponding to this $\Delta_{0}$ :

$$
\bar{x}\left(\Delta_{0}\right)=(1-\tau)\left(1+\frac{(1-\beta)(1-\lambda)}{\beta}\right)-\frac{(1-\tau)^{1-\beta}(1-\lambda)^{1-\beta}}{\beta} .
$$




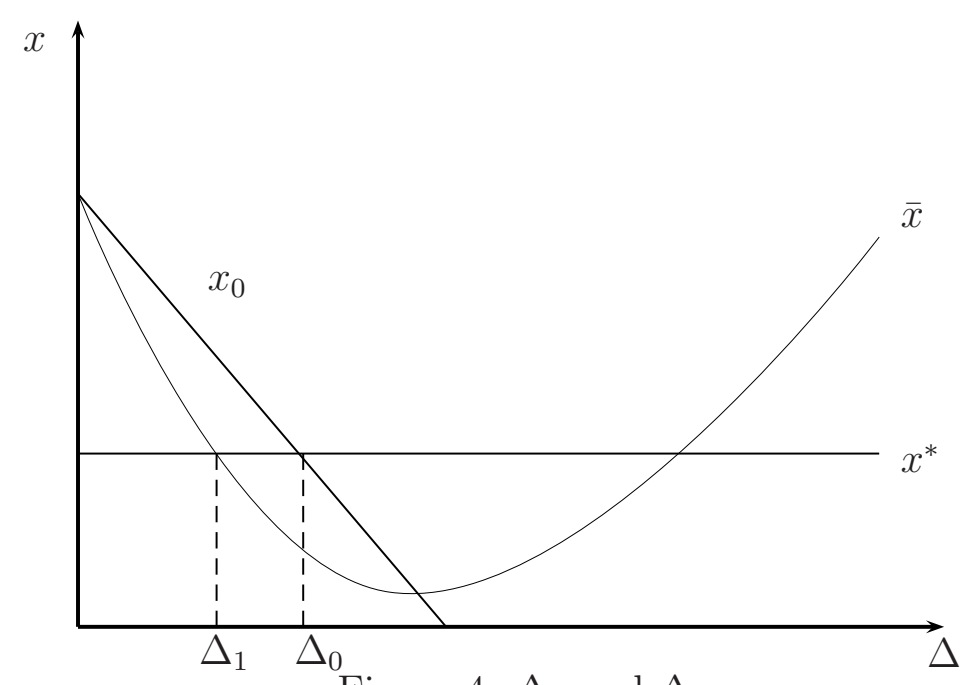

Figure 4: $\Delta_{0}$ and $\Delta_{1}$

Thus, $\bar{x}\left(\Delta_{0}\right)<x^{*}$ if and only if:

$$
(1-\tau)\left(1+\frac{(1-\beta)(1-\lambda)}{\beta}\right)-\frac{(1-\tau)^{1-\beta}(1-\lambda)^{1-\beta}}{\beta}<\lambda(1-\tau),
$$

or

$$
\frac{(1-\tau)(1-\lambda)}{\beta}<\frac{(1-\tau)^{1-\beta}(1-\lambda)^{1-\beta}}{\beta}
$$

which is true as $(1-\tau)^{\beta}(1-\lambda)^{\beta}<1$.

So we have proved that, for $\Delta<\Delta_{0}$, there is a unique intersection between $x^{*}$ and $\bar{x}$ as represented in figure 4 . We now just need to determine $\Delta_{1}$. Let $\bar{\Delta}$ be the value of $\Delta$ such that $\bar{x}(\bar{\Delta})=\hat{x}(\bar{\Delta})$ and $\Delta^{*}$ be such that $x^{*}=\hat{x}\left(\Delta^{*}\right)$ :

$$
\bar{\Delta}=\frac{(1-\beta)(1-\tau)}{\beta(1+n)}\left(\frac{1-\alpha}{(1-\phi) \alpha+\tau(1-\alpha)}\right)^{\frac{1}{\beta}} \tau^{\frac{1-\beta}{\beta}}
$$

and

$$
\Delta^{*}=\frac{(1-\lambda)(1-\tau)(1-\beta)(1-\alpha)}{(1+n)((1-\phi) \alpha+\beta \tau(1-\alpha))}
$$

The equilibrium is constrained when $\bar{\Delta}$ is higher than $\Delta^{*}$ which gives the condition on $\phi$.

We obtain $\bar{\phi}$ as solution of $\Delta^{*}=\bar{\Delta}$ which means that:

$$
\frac{1}{\beta}\left(\frac{1-\alpha}{(1-\bar{\phi}) \alpha+\tau(1-\alpha)}\right)^{\frac{1}{\beta}} \tau^{\frac{1-\beta}{\beta}}=\frac{(1-\lambda)(1-\alpha)}{((1-\bar{\phi}) \alpha+\beta \tau(1-\alpha))} .
$$


Taking the log of this equation and differentiating with respect to $\tau$ and $\bar{\phi}$ gives:

$$
\begin{array}{r}
d \tau\left(-\frac{1-\alpha}{(1-\bar{\phi}) \alpha+\tau(1-\alpha)}+\frac{\beta^{2}(1-\alpha)}{(1-\bar{\phi}) \alpha+\beta \tau(1-\alpha)}+\frac{1-\beta}{\tau}\right)+ \\
d \bar{\phi}\left(\frac{\alpha}{(1-\bar{\phi}) \alpha+\tau(1-\alpha)} \frac{\beta \alpha}{(1-\bar{\phi}) \alpha+\beta \tau(1-\alpha)}\right)=0
\end{array}
$$

or equivalently:

$$
\begin{aligned}
& d \tau\left(\frac{(1-\bar{\phi}) \alpha^{2}(1-\beta)}{\tau((1-\bar{\phi}) \alpha+\tau(1-\alpha))((1-\bar{\phi}) \alpha+\beta \tau(1-\alpha) \tau)}\right)+ \\
& d \bar{\phi}\left(\frac{\alpha^{2} \beta}{((1-\bar{\phi}) \alpha+\tau(1-\alpha))((1-\bar{\phi}) \alpha+\beta \tau(1-\alpha) \tau)}\right)=0 .
\end{aligned}
$$

From which we deduce the derivative of $\bar{\phi}$ with respect to $\tau$ :

$$
\frac{d \bar{\phi}}{d \tau}=-\frac{(1-\bar{\phi})(1-\beta) \tau}{\alpha^{2} \beta}
$$

which is negative.

\section{Proof of Proposition 4}

We consider, as in the Proposition, three different cases.

i) In the case where the economy is initially constrained, from Proposition 3 the economy remains constrained when $\phi$ is increasing.

In the long run, at the steady state $\bar{k}$, equations (22) and (28) can be rewritten:

$$
\bar{k}=\left(\frac{R_{W}}{A \bar{x}(1-\alpha)}\right)^{\frac{1}{\alpha}} e^{\frac{1-\lambda}{\alpha}}
$$

and

$$
\bar{k}=\left(\frac{\bar{\Delta} \alpha}{A}\right)^{\frac{1}{1-\alpha}} \bar{e}^{\frac{-\lambda}{1-\alpha}}
$$

From these two equations, we can eliminate $\bar{k}$ and deduce an expression for $\bar{e}$ depending only on $\bar{\Delta}$ as, from equation (21), we know that $\bar{x}$ is a function of $\bar{\Delta}$ :

$$
\bar{e}^{\frac{1-\lambda}{\alpha}+\frac{\lambda}{1-\alpha}}=\left(\frac{\bar{\Delta} \alpha}{A}\right)^{\frac{1}{1-\alpha}}\left(\frac{A \bar{x}(1-\alpha)}{R_{W}}\right)^{\frac{1}{\alpha}} \equiv \Phi(\bar{\Delta}) .
$$

Since, from equation (48), we know that $\bar{\Delta}$ is increasing with $\phi$ and as the growth rate is increasing with $\bar{e}$, if we prove that $\bar{e}$ is decreasing with $\bar{\Delta}$, this implies that the 
growth rate $g$ is decreasing with $\phi$. Thus, to show that increasing openness decreases long term growth, we just have to show that $\Phi^{\prime}(\bar{\Delta})>0$ for all $\bar{\Delta}$ in its definition set.

To be more precise, from Figure 2 , it is clear that $\bar{\Delta} \in\left[\Delta_{\min }, \Delta_{\max }\right]$ where $\Delta_{\min }$ is the value of $\Delta$ such as $\bar{x}=x^{*}$ and $\Delta_{\max }$ is the value of $\Delta$ such that $\bar{x}=x_{0}, x_{0}$ being the value of $x$ making savings zero.

Lemma 2. The value $\Delta_{\max }$ corresponds to the minimum of the function $\bar{x}(\Delta)$, and is characterized by:

$$
\Delta_{\max }=\frac{(1-\beta)(1-\tau)}{\tau(1+n) \beta} .
$$

The value $\Delta_{\min }$ is characterized by:

$$
\eta\left(\Delta_{\min }\right)=(1-\lambda)(1-\tau)
$$

Proof:

From equation (21), the minimum of the function $\bar{x}(\Delta)$ is

$$
\frac{\eta(\Delta)}{\Delta}=\frac{\beta}{1-\beta} \tau(1+n)
$$

From equation (47),

$$
x_{0}(\Delta)=1-\tau-\frac{\beta}{1-\beta} \tau(1+n) \Delta .
$$

And then $x_{0}=\bar{x}$ iff

$$
1-\tau-\frac{\beta}{1-\beta} \tau(1+n) \Delta=1-\tau-\eta \beta .
$$

From equations (21) and (61), we can deduce the following expression:

$$
\zeta \Delta_{\max }^{-\beta}=\frac{\tau(1+n)}{1-\beta},
$$

with

$$
\zeta \equiv\left(\frac{\tau(1+n)}{1-\beta}\right)^{1-\beta}\left(\frac{1-\tau}{\beta}\right)^{\beta}
$$

from which we can obtain the expression of $\Delta_{\max }$.

The lower bound $\Delta_{\min }$ is the solution of the equation $\bar{x}\left(\Delta_{\min }\right)=x^{*}\left(\Delta_{\min }\right)$ which means that

$$
\lambda(1-\tau)=1-\tau-\eta\left(\Delta_{\min }\right)
$$

and is equivalent to equation (61). 
Now that we have clearly identified the interval where $\bar{\Delta}$ belongs, we compute $\Phi^{\prime}(\bar{\Delta})$ and prove it is always positive.

$$
\Phi^{\prime}(\bar{\Delta})=\Phi(\bar{\Delta})\left(\frac{1}{(1-\alpha) \bar{\Delta}}+\frac{1}{\alpha} \frac{d \bar{x}}{d \bar{\Delta}} \frac{1}{\bar{x}}\right)
$$

As $\Phi(\bar{\Delta})>0$, then $\Phi^{\prime}(\bar{\Delta})<0$ iff:

$$
\frac{1}{(1-\alpha) \bar{\Delta}}+\frac{1}{\alpha} \frac{d \bar{x}}{d \bar{\Delta}} \frac{1}{\bar{x}}<0
$$

with

$$
\frac{d \bar{x}}{d \bar{\Delta}}=-\frac{d \eta(\bar{\Delta})}{d \bar{\Delta}}=-(1-\beta) \frac{\eta(\bar{\Delta})}{\bar{\Delta}}+\beta \tau(1+n) .
$$

Substituting in equation $(66), \Phi^{\prime}(\bar{\Delta})<0$ iff

$$
\alpha(1-\tau-\eta(\bar{\Delta}))+(1-\alpha)(\beta \tau(1+n) \bar{\Delta}-(1-\beta) \eta(\bar{\Delta}))<0,
$$

iff

$$
(1-\beta+\alpha \beta) \eta(\bar{\Delta})-(1-\alpha)(1+n) \beta \tau \bar{\Delta}-\alpha(1-\tau)>0 .
$$

Moreover, from equation (21), we know that

$$
\eta(\bar{\Delta})=\zeta \bar{\Delta}^{1-\beta}-\tau(1+n) \bar{\Delta},
$$

with $\zeta=\left(\frac{\tau(1+n)}{1-\beta}\right)^{1-\beta}\left(\frac{1-\tau}{\beta}\right)^{\beta}$.

Thus $\Phi^{\prime}(\bar{\Delta})<0$ iff $\Psi(\bar{\Delta})>0$, with

$$
\Psi(\bar{\Delta}) \equiv(1-\beta(1-\alpha)) \zeta \bar{\Delta}^{1-\beta}-(1+n) \tau \bar{\Delta}-\alpha(1-\tau) .
$$

As $\bar{\Delta}$ belongs to the interval $\left(\Delta_{\min }, \Delta_{\max }\right)$, we compute the value of the function $\Psi(\bar{\Delta})$ at the two extremes.

$$
\begin{gathered}
\Psi\left(\Delta_{\min }\right)=(1-\tau)((1-\lambda)(1-\beta(1-\alpha))-\alpha)-(1-\alpha)(1+n) \beta \tau \Delta_{\min } \\
\Psi\left(\Delta_{\max }\right)=\tau(1+n) \Delta_{\max }\left(\frac{\beta \alpha}{1-\beta}\right)-\alpha(1-\tau)=0 .
\end{gathered}
$$

As

$$
\Psi^{\prime}(\bar{\Delta})=(1-\beta)(1-\beta(1-\alpha)) \zeta \bar{\Delta}^{-\beta}-(1+n) \tau
$$

and

$$
\Psi^{\prime \prime}(\bar{\Delta})=-\beta(1-\beta)(1-\beta(1-\alpha)) \zeta \bar{\Delta}^{-\beta_{1}} .
$$

Function $\Psi^{\prime \prime}(\bar{\Delta})$ is concave. Then if $\Psi^{\prime}\left(\Delta_{\text {min }}\right)<0$, the slope of $\Psi^{\prime}(\bar{\Delta})$ being always decreasing on the interval $\left(\Delta_{\min }, \Delta_{\max }\right)$, that means that $\Psi^{\prime}(\bar{\Delta})$ is always negative and then $\Psi\left(\Delta_{\min }\right) \geq \Psi(\bar{\Delta}) \geq 0$. And as from equation (61)

$$
\frac{\eta\left(\Delta_{\min }\right)}{\Delta_{\min }}=\frac{\beta}{1-\beta} \tau(1+n)
$$


then

$$
\Psi^{\prime}\left(\Delta_{\text {min }}\right)=-\beta(1-\alpha)(1+n) \tau<0 .
$$

We thus obtain that $\Psi(\bar{\Delta})>0$ for any $\bar{\Delta} \in\left(\Delta_{\min }, \Delta_{\max }\right)$, meaning that $\Phi^{\prime}(\bar{\Delta})>0$ and thus that $g$ is decreasing with $\phi$.

ii) The economy is initially unconstrained and remains unconstrained with openness. From Proposition 2, a rise in $\phi$ makes $k^{*}$ increasing. From equation (9), we know $e^{*}=\left(\frac{\lambda(1-\tau) A(1-\alpha)}{R_{W}}\right)^{\frac{1}{1-\lambda}} k^{* \frac{\alpha}{1-\lambda}}$, and then $e^{*}$ increases with $\phi$ and so does $g$.

iii) From i), in an initially unconstrained economy, a rise in $\phi$ increases the growth rate. When the economy becomes constrained, from ii), the growth rate decreases with $\phi$. From equations (6) and (17), when $\phi=\bar{\phi}$, as $\bar{x}=x^{*}$ and $\bar{\Delta}=\Delta^{*}$, then $\bar{e}=e^{*}$ and the growth rate is maximized. 


\section{References}

[1] Aghion, Philippe and Comin, Diego and Howitt, Peter and Tecu, Isabel, 2009. "When Does Domestic Saving Matter for Economic Growth?" Harvard Business School Working Paper, No. 09080.

[2] Aizenman, Joshua and Sushko, Vladyslav, 2011. "Capital Flow Types, External Financing Needs, and Industrial Growth: 99 countries, 1991-2007," NBER Working Papers 17228, National Bureau of Economic Research, Inc.

[3] Angeletos, George-Marios and Panousi, Vasia, 2011. "Financial integration, entrepreneurial risk and global dynamics," Journal of Economic Theory, vol. 146(3), pages 863-896, May.

[4] Aoki, Kosuke and Benigno, Gianluca and Kiyotaki, Nobuhiro, 2010. "Adjusting to Capital Account Liberalization," CEP Discussion Papers dp1014, Centre for Economic Performance, LSE.

[5] Arellano, Cristina and Mendoza, Enrique G., 2002. "Credit Frictions and 'Sudden Stops' in Small Open Economies: An Equilibrium Business Cycle Framework for Emerging Markets Crises," NBER Working Papers 8880, National Bureau of Economic Research, Inc.

[6] Azariadis, Costas and Lambertini, Luisa, 2003. "Endogenous Debt Constraints in Lifecycle Economies," Review of Economic Studies, vol. 70(3), pages 461-487, 07 .

[7] Bekaert, Geert and Harvey, Campbell R. and Lundblad, Christian, 2005. "Does financial liberalization spur growth?," Journal of Financial Economics, vol. 77(1), pages 3-55, July.

[8] Bekaert, Geert and Harvey, Campbell R. and Lundblad, Christian, 2011. "Financial Openness and Productivity," World Development, vol. 39(1), pages 1-19, January.

[9] Broner, Fernando A. and Ventura, Jaume, 2010. "Rethinking the Effects of Financial Liberalization," NBER Working Papers 16640, National Bureau of Economic Research, Inc.

[10] Buera, Francisco J. and Shin, Yongseok, 2009. "Productivity Growth and Capital Flows: The Dynamics of Reforms," NBER Working Papers 15268, National Bureau of Economic Research, Inc. 
[11] Bulow, Jeremy and Rogoff, Kenneth (1989), "Sovereign debt: is to forgive to forget?," American Economic Review 79, 43-50.

[12] Caballero, Ricardo J. and Farhi, Emmanuel and Gourinchas, Pierre-Olivier, 2008. "An Equilibrium Model of 'Global Imbalances' and Low Interest Rates," American Economic Review, vol. 98(1), pages 358-93, March.

[13] Carroll, Christopher D. and Jeanne, Olivier, 2009. "A Tractable Model of Precautionary Reserves, Net Foreign Assets, or Sovereign Wealth Funds," NBER Working Papers 15228, National Bureau of Economic Research, Inc.

[14] Caselli, Francesco, 2005. "Accounting for Cross-Country Income Differences," in: Philippe Aghion and Steven Durlauf (eds.), Handbook of Economic Growth, edition 1, volume 1, chapter 9, pages 679-741, Elsevier.

[15] Chinn, Menzie D. and Ito, Hiro, 2008. "A New Measure of Financial Openness," Journal of Comparative Policy Analysis, vol. 10(3), pages 309-322, September.

[16] Christopoulos, Dimitris K., Gente, Karine and León-Ledesma, Miguel A., 2012. "Net foreign assets, productivity and real exchange rates in constrained economies," European Economic Review, vol. 56(3), pages 295-316 April.

[17] Coeurdacier, Nicolas, Guibaud, Stephane and Jin, Keyu, 2013. "Credit Constraints and Growth in a Global Economy," mimeo, London School of Economics.

[18] De La Croix David and Michel, Philippe, 2007. "Education and growth with endogenous debt constraints," Economic Theory, vol. 33(3), pages 509-530, December.

[19] Eaton, Jonathan and Gersovitz, Mark, 1981. "Debt with potential repudiation: theoretical and empirical analysis," Review of Economic Studies 48, 289-309.

[20] Gomes, Victor and Bugarin, Mirta N.S. and Ellery-Jr, Roberto, 2005. "Long-run Implications of the Brazilian Capital Stock and Income Estimates," Brazilian Review of Econometrics, vol. 25(1), pages 6788, May.

[21] Gourinchas, Pierre-Olivier and Jeanne, Olivier, 2013. "Capital Flows to Developing Countries: The Allocation Puzzle," Review of Economic Studies 80(4), pages 1484-1515, October.

[22] Henry, Peter Blair, 2007. "Capital Account Liberalization: Theory, Evidence, and Speculation," Journal of Economic Literature, vol. 45(4), pages 887-935, December. 
[23] Kehoe, Timothy J and Levine, David K, 1993. "Debt-Constrained Asset Markets," Review of Economic Studies, vol. 60(4), pages 865-88, October.

[24] Kiyotaki, Nobuhiro and Moore, John, 1997. "Credit Cycles," Journal of Political Economy, vol. 105(2), pages 211-248, April.

[25] Kose, Ayhan M. and Prasad, Eswar S. and Terrones, Marco E., 2009. "Does openness to international financial flows raise productivity growth?," Journal of International Money and Finance, vol. 28(4), pages 554-580, June.

[26] Kose, Ayhan M. and Prasad, Eswar S. and Taylor, Ashley D., 2011. "Thresholds in the process of international financial integration," Journal of International Money and Finance, vol. 30(1), pages 147-179, February.

[27] Lane, Philip R. and Milesi-Ferretti, Gian-Maria, 2007. "The external wealth of nations mark II: Revised and extended estimates of foreign assets and liabilities, 1970-2004," Journal of International Economics, Elsevier, vol. 73(2), pages 223250, November.

[28] McKinsey Global INstitute, 2013. Financial globalization: retreat or reset?. McKinsey Global Institute.

[29] Mendoza, Enrique G. and Quadrini, Vincenzo and Ríos-Rull, José-Víctor, 2009. "Financial Integration, Financial Development, and Global Imbalances," Journal of Political Economy, vol. 117(3), pages 371-416, 06.

[30] Prasad, Eswar S. and Rajan, Raghuram G. and Subramanian, Arvind, 2007. "Foreign Capital and Economic Growth," Brookings Papers on Economic Activity, vol 38(1), pages 153-230.

[31] Obstfeld, Maurice, 2009. "International Finance and Growth in Developing Countries: What Have We Learned?," IMF Staff Papers, vol. 56(1), pages 63-111.

[32] OECD, 2009. "Pensions at a Glance". OECD.

[33] Sandri, Damiano, 2010. "Growth and Capital Flows with Risky Entrepreneurship," IMF Working Papers 10/37, International Monetary Fund.

[34] Song, Zheng and Storesletten, Kjetil and Zilibotti, Fabrizio, 2011. "Growing Like China," American Economic Review, vol. 101(1), pages 196-233, February. 